\title{
Review
}

Matteo Tonezzer*, Dang Thi Thanh Le, Lai Van Duy, Nguyen Duc Hoa, Flavia Gasperi, Nguyen Van Duy*, and Franco Biasioli

\section{Electronic noses based on metal oxide nanowires: A review}

https://doi.org/10.1515/ntrev-2022-0056

received October 29, 2021; accepted January 16, 2022

\begin{abstract}
Metal oxides are ideal for the fabrication of gas sensors: they are sensitive to many gases while allowing the device to be simple, tiny, and inexpensive. Nonetheless, their lack of selectivity remains a limitation. In order to achieve good selectivity in applications with many possible interfering gases, the sensors are inserted into an electronic nose that combines the signals from nonselective sensors and analyzes them with multivariate statistical algorithms in order to obtain selectivity. This review analyzes the scientific articles published in the last decade regarding electronic noses based on metal oxide nanowires. After a general introduction, Section 2 discusses the issues related to
\end{abstract}

* Corresponding author: Matteo Tonezzer, Department of Food Quality and Nutrition, Research and Innovation Centre, Fondazione Edmund Mach, 38010, San Michele all' Adige, TN, Italy; Center Agriculture Food Environment, University of Trento/Fondazione Edmund Mach, Via E. Mach 1, 38010 San Michele all'Adige, Italy; National Research Council (CNR), Institute of Materials for Electronics and Magnetism (IMEM), Via alla Cascata 56/C, 38123 Trento, Italy, e-mail: tonezzer@fbk.eu

* Corresponding author: Nguyen Van Duy, International Training Institute for Materials Science (ITIMS), Hanoi University of Science and Technology (HUST), No. 1, Dai Co Viet Str., Hanoi, Vietnam, e-mail: nguyenvanduy@itims.edu.vn

Dang Thi Thanh Le, Nguyen Duc Hoa: International Training Institute for Materials Science (ITIMS), Hanoi University of Science and Technology (HUST), No. 1, Dai Co Viet Str., Hanoi, Vietnam Lai Van Duy: Center Agriculture Food Environment, University of Trento/ Fondazione Edmund Mach, Via E. Mach 1, 38010 San Michele all'Adige, Italy; International Training Institute for Materials Science (ITIMS), Hanoi University of Science and Technology (HUST), No. 1, Dai Co Viet Str., Hanoi, Vietnam; Department of Electronic Engineering, University of Rome Tor Vergata, Via del Politecnico 1, 00133, Rome, Italy Flavia Gasperi: Department of Food Quality and Nutrition, Research and Innovation Centre, Fondazione Edmund Mach, 38010, San Michele all' Adige, TN, Italy; Center Agriculture Food Environment, University of Trento/Fondazione Edmund Mach, Via E. Mach 1, 38010 San Michele all'Adige, Italy

Franco Biasioli: Department of Food Quality and Nutrition, Research and Innovation Centre, Fondazione Edmund Mach, 38010, San

Michele all' Adige, TN, Italy poor intrinsic selectivity. Section 3 briefly reviews the main algorithms that have hitherto been used and the results they can provide. Section 4 classifies the recent literature into fundamental research, agrifood, health, security. In Section 5, the literature is analyzed regarding the metal oxides, the surface decoration nanoparticles, the features that differentiate the sensors in a given array, the application for which the device was developed, the algorithm used, and the type of information obtained. Section 6 concludes by discussing the present state and points out the requirements for their use in real-world applications.

Keywords: electronic nose, metal oxide, nanowire, sensor array, gas sensor, machine learning

\section{Introduction}

Recently, gas sensors are increasingly needed in many areas of human life, from monitoring indoor and outdoor air quality, industrial processes, food quality, and even to carry out noninvasive diagnostic screening. The importance of the gaseous component in human life is confirmed by the scientific interest, which has increased a lot over the years from the beginning of the 1970s to date. A search for "gas sensors" in Scopus (Figure 1a) shows that the first article on this topic was published in 1969, while 12,420 were published last year. The plot shows that the growth is remarkable and constant [1]. Interest gradually increased from the 1970s to the mid-2000s and then escalated more rapidly. The advent of nanotubes and nanowires, with the concurrent increase in performance, could be the driving force of this growing attention. In fact, the scientific articles that study nanowire-based gas sensors are more than a quarter of the total, and as can be seen in Figure $1 \mathrm{~b}$, they too are constantly growing [1].

This review focuses on electronic noses based on metal oxide nanowires since metal oxide semiconductors are the most used materials for solid-state gas sensors and nanowires, with their very high surface/volume ratio reaching unthinkable performance for previous generations (thick 

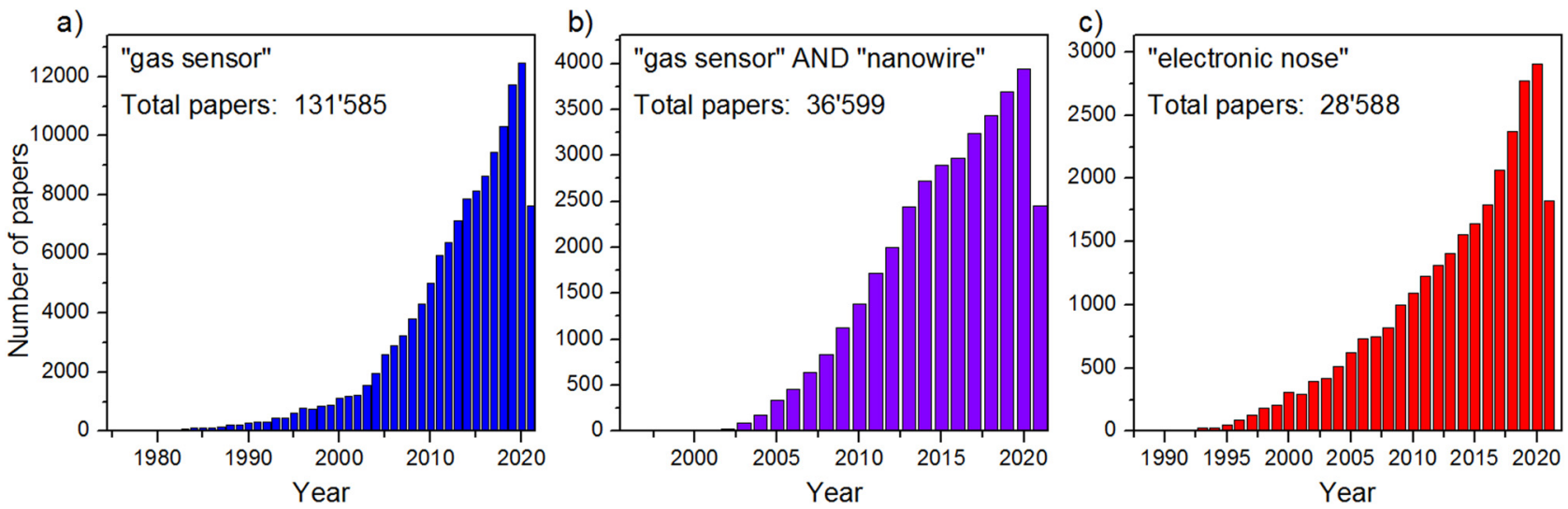

Figure 1: Trend in the number of scientific articles per year found searching for (a) "gas sensor", (b) "gas sensor AND nanowire", and (c) "electronic nose" on Scopus [1]

and thin films). Resistive sensors based on metal oxide nanowires are indeed ideal in many respects, as they are tiny and light, cheap to manufacture and operate, and sensitive to most gases and volatiles. The latter property is double-edged since sensitivity to almost any gas means at the same time a lack of selectivity. Overcoming the lack of selectivity of semiconductor chemoresistors, inherent in any device with a one-dimensional output signal, is the main challenge to make these devices ideal for widespread use in many fields of application. In practice, any sensor that has a single value as its output (usually a ratio between a physical quantity in the presence and absence of the target gas) is inherently nonselective. In the case of resistive sensors, the response is usually defined as the ratio between the resistance of the sensor in the presence of a target gas $\left(R_{\mathrm{G}}\right)$ and its resistance in air $\left(R_{\mathrm{A}}\right): R_{\mathrm{G}} / R_{\mathrm{A}}$.

The selectivity of these sensors is limited to distinguishing the two large families of gases: oxidizing and reducing gases since in one case the resistance increases and in the other it decreases, and therefore, the response will be higher or lower than 1 .

For this reason, the most common approach to obtain selective devices is to combine different resistive sensors in an array and study their responses together, in order to recognize the typical trends of the various gases. These instruments have taken the name of electronic noses because they replicate the pattern of operation inside the nose of mammals. Also in the case of animals, the responses of nonselective or partially selective receptors are combined and processed in order to associate typical patterns to different volatile compounds. In a similar fashion, an electronic nose achieves a certain capability to recognize different gases and estimate their concentration (usually after a calibration or "training" phase) combining the response of sensors with a much poorer selectivity). As can be seen in Figure 1c, the interest in electronic noses started in the 1990s and continues to grow, almost exponentially [1]. Although the interest is extensive, both scientific and economic, these devices still have limited applications, and the advancement of machine learning will certainly support their success.

Despite the strong interest in both nanowire-based gas sensors and electronic noses, scientific papers studying nanowire-based electronic noses are still very few. This can be explained by the fact that nanowires have better performance than previous generations (thin films) but also lower stability and reliability over time, and are therefore less mature for practical applications. Alternatively, the reason can be the multidisciplinarity necessary for this type of tool, which combines the latest developments in nanoscience and nanotechnology, and machine learning. This requires strong collaboration between groups with very different expertise and can initially slow down the growth of the sector.

In this review, we analyze the recent relevant scientific literature, trying to understand how mature the field is and what are the bottlenecks that limit its development. The analysis of the published articles shows that the development obtained by nanosciences in controlling the structural, morphological, and compositional properties of nanomaterials is not matched by the computer processing counterpart. For this reason, the review focuses on the "brains" used so far for electronic noses based on metal oxide nanowires, and on the type of information obtained from them. In fact, the "brain" of the electronic noses, or rather the approach to data mining or data visualization, is the key component that determines its performance. 
As will become clear in the following sections, case studies from the literature use very different approaches to the evaluation of sensor performances, from simple visual inspection of the data to advanced data mining methods, with their merits and drawbacks. A critical review of these studies with a focus on misconception and real application needs seems important to support a better comparison of the reported performances and more efficient in the development of electronic noses based on nanowires. We think that such an analysis can support groups working on chemosensors on their way for the realization of successful electronic noses by indicating possible strategies and achievable results.

\section{Intrinsic selectivity}

Metal oxides have been shown to be excellent gas detection materials since the 1960s [2]. Technological development has made it possible to move from thick films to thin films and then to nanostructured materials. Nanostructures, including nanowires, are characterized by having an enormous surface/volume ratio, and therefore, the effect of the depletion that occurs at the surface is much more intense. Unfortunately, together with many advantages, these materials also carry two major defects: high working temperature and low selectivity. Working temperature is a minor problem that was initially solved with integrated microheaters and recently addressed with surface decoration. The surface of MOs nanostructures is decorated with metal nanoparticles or other MOs in order to exploit the spillover effect, the catalysis, and the additional junctions created at the interfaces between the two materials. Surface decoration is commonly used to increase the response and lower the working temperature of sensors [3]. The increase in the response and the lowering of the working temperature are reproducible effects, but the influence on the other performance parameters, including selectivity, is still not yet clear because the contradictory indications of the literature make it difficult to identify clear trends [4]. Tshabalala et al. investigated how the sensing mechanisms change with temperature [5] by photoluminescence and X-ray photoelectron spectroscopy. They were able to demonstrate that the selective response of the $\mathrm{TiO}_{2}$ nanowire-based sensor to $\mathrm{C}_{7} \mathrm{H}_{10}$ at $23^{\circ} \mathrm{C}$ is defect-dependent, while the selective response to $\mathrm{C}_{8} \mathrm{H}_{10}$ at $150^{\circ} \mathrm{C}$ was not defect-dependent. This demonstrates that among the many reactions that take place at the gassolid interface, the main sensing mechanism can vary significantly also as a function of temperature, leading to selectivity toward different gases as the temperature varies. Similar behaviors (selectivity varying by changing the working temperature) were also observed by Kim et al. [6] toward $\mathrm{C}_{7} \mathrm{H}_{10}$ and $\mathrm{C}_{7} \mathrm{H}_{8}$ using $\mathrm{NiO}$ at 350 and $400^{\circ} \mathrm{C}$, and by Motsoeneng et al. [7] toward $\mathrm{C}_{3} \mathrm{H}_{7} \mathrm{OH}$ and $\mathrm{C}_{2} \mathrm{H}_{5} \mathrm{OH}$ using $\mathrm{SnO}_{2}$ at 75 and $150^{\circ} \mathrm{C}$. Kim et al. explained that the tuning of selectivity to $p$-xylene at $350^{\circ} \mathrm{C}$ or to toluene at $400^{\circ} \mathrm{C}$ was achieved by controlling the balance between the catalytic promotion of the gas in more active species and the oxidation in less reactive species depending on the temperature of exercise [6]. Motsoeneng et al. showed that the selectivity toward different gases depends both on the morphology of the nanostructures and on the working temperature. Also, in this case, PL and XPS confirmed that the density of defects in nanostructures depends on their morphology, and influences the response of the sensor [7]. As can be seen, there are various detection mechanisms that often act simultaneously and, although they are being studied, unfortunately, the results obtained do not yet paint a homogeneous picture. The importance of the dimensions of the nanomaterial is well established since the response of the sensor depends on the thickness of the depletion layer (which is fixed) in relation to the thickness of the nanostructure. For this reason, thin films perform much better than thick films and the new 2D materials promise further improvement [8]. The modulation mechanism of the depletion layer is accepted as the source of the electrical response of the sensor and studied extensively. By approximating the bending of the bands with a simple step function, it can be seen that as the thickness of the nanowire decreases closer to the depth of the depletion layer, the more the sensor response increases [9].

Figure 2a shows the section of a semiconductor metal oxide nanowire in air (left column) and in the presence of gas (right column). Since the depth of the depletion layer is constant (red arrow), as the radius of the nanowire (green arrow) decreases, the sensor response (ratio between the purple circle on the left and the one on the right) increases. Liu et al. demonstrated that the sensor response reaches its maximum peak when the thickness of the nanostructure equals the depletion layer [10]. Figure $2 b$ illustrates how the effect of the modulation mechanism of the depletion layer differs as the dimensionality of the nanostructures varies. The mechanism acts in a non-negligible way only on the nanometric dimensions of the material, and therefore, a 2D structure (a thin plate) will be depleted only in one dimension, while a $1 \mathrm{D}$ nanowire will be depleted in two dimensions and a OD nanoparticle in all three dimensions [11]. The main problem with metal oxides therefore remains selectivity. Many groups work on resistive gas sensors based on different metal oxides, both 
a)

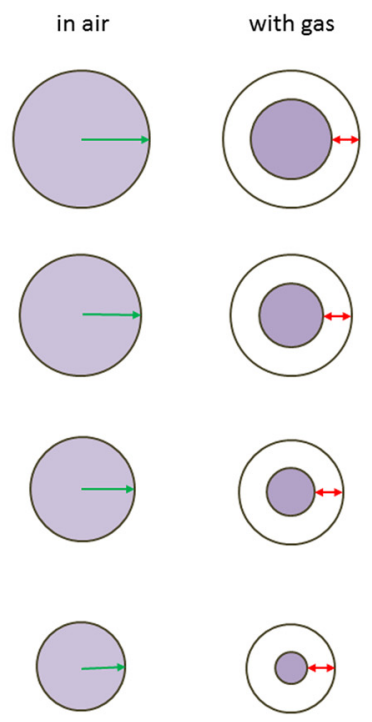

b)

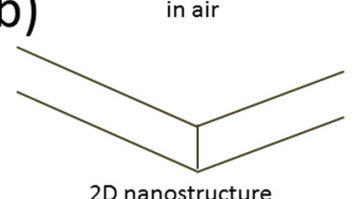

2D nanostructure
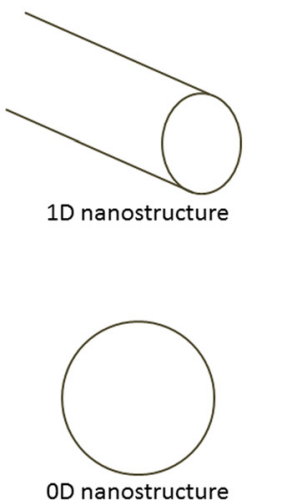
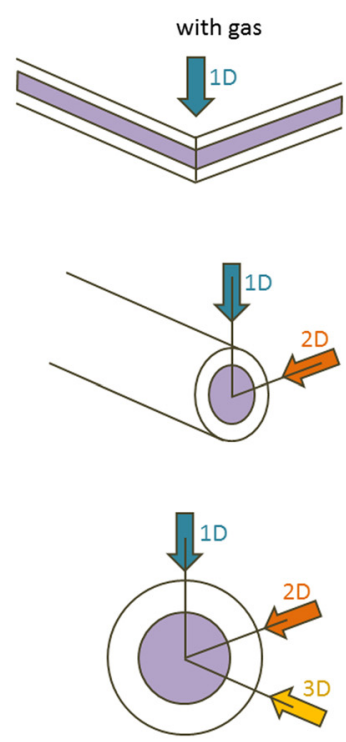

Figure 2: (a) Section of a nanowire in air and in the presence of gas. The white annular section is the depletion layer, while the purplecolored part contributes to the signal. (b) The modulation of the depletion layer acts on the number of nanometric dimensions.

$\mathrm{n}$-type and p-type, but the results in the literature regarding selectivity are rarely in agreement. In order to assess whether there is agreement about the selectivity of the main metal oxides toward specific gases, we have carried out a survey of the recent scientific literature, which is shown in Figure 3.

As can be seen in Figure 3, there is no agreement in the literature for any metal oxides. The maximum agreement reached by the various scientific articles examined is $50 \%$ in the case of $\mathrm{SnO}_{2}, \mathrm{TiO}_{2}$, and $\mathrm{In}_{2} \mathrm{O}_{3}$, while the minimum agreement is $25 \%$ for $\mathrm{Co}_{3} \mathrm{O}_{4}$ and $\mathrm{CuO}$. This demonstrates that the selectivity of metal oxides depends on many parameters, and it is currently impossible to consider a certain selective metal oxide for a certain gas.

\section{The brain of the electronic nose: visualization methods and algorithms}

A key component of an electronic nose is its "brain": an array of nonselective or low-selective sensors cannot achieve true selectivity if the responses are not intelligently processed and combined. The data processing carried out on the data matrix extracted from a sensor array is fundamental to obtain good performance but it is also a rather distant topic from materials science. For this reason, research groups that were working on traditional gas sensors based on nanowires had to undertake interdisciplinary collaborations or develop their own expertise in this field. However, both processes (developing interdisciplinary collaborations and building your own skills) are complex and time-consuming. This explains why the "brain" of the electronic nose is to date its least developed element despite being the most important. For this reason, together with the different machine learning algorithms, Section 2.1 has been inserted to describe the most basic methods that have been used in recent years to demonstrate the capacity for selectivity. These systems have in common the fact that they are visual methods, in which it is necessary for the reader to observe a graph and reason. In this way, the human eye and brain (which is still the best pattern recognition system, at least in two dimensions) are exploited as part of the sensing system. In the next subsections, the methods used in the articles studied have been listed according to the objectives they achieve: mere feasibility, qualitative classification, qualitative quantification, real classification, and real quantification. This distinction will serve to discuss the current state of development of nanowire-based electronic noses, as the level of ability to achieve real-world classification and possibly quantification is a strictly necessary requirement for real-world applications.

\subsection{Proof of concept}

Some publications focus only on the feasibility of an electronic nose by showing how the responses of the sensors 
that form the array vary as the tested gas or gas mixture varies. This can be done by visual inspection of the trend of a bar plot or a box plot, and how this trend (fingerprint) is different for each gas. Similarly, the different shapes that sensor responses show in a radar plot for different gases can be used to distinguish them. These methods are not based on algorithms of any kind but on the ability of the human eye and brain to distinguish differences and similarities, so they can only be considered proof of concept.

\subsection{Principal component analysis (PCA)}

This very old technique, which is gaining more and more interest in the field of sensors, is a data reduction method used in multivariate statistics. The aim of this technique is to reduce the number of variables describing a data set to a smaller number of latent variables, with a limited loss of information. In practice, it is a linear transformation that projects the $N$ original variables into a new coordinate system (still of dimension $N$ ) in which the
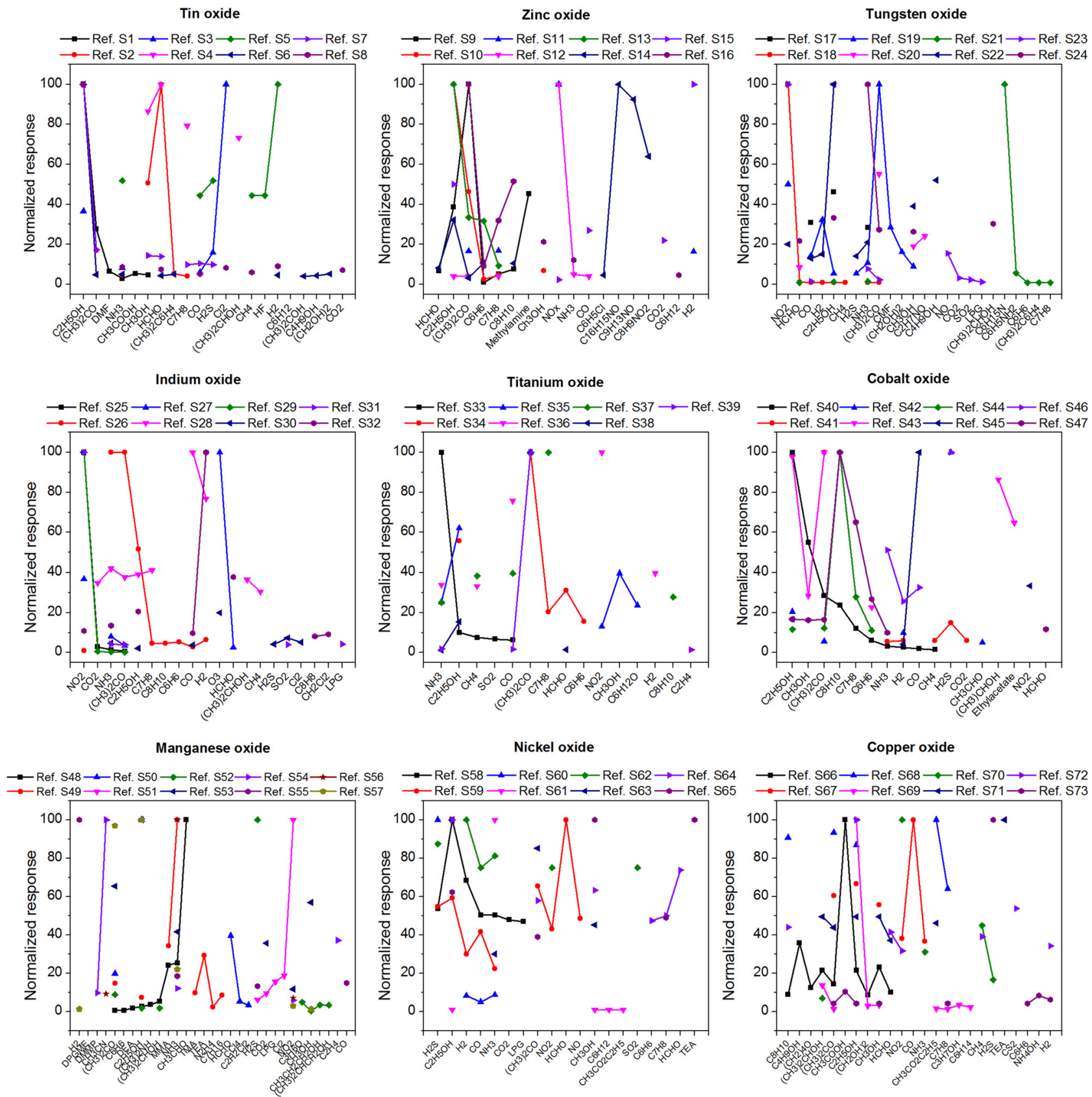

Figure 3: Selectivity of the main metal oxides toward the studied gases. The response in each reference was normalized (the highest response was set to 100). The references from which the data are taken are given in the Supplementary Information. 
new variable with the greatest variance is projected onto the first axis, the new variable, second by variance, onto the second axis and so on. In this way, it is possible to reduce the number of variables (from $N$ to $M<N$ ) while keeping as much information as possible contained in the original variables. The original purpose (to reduce a too large data set) is usually not what it is used for in the case of e-noses: as we shall see, here it is often used to reduce a small number of variables (6-12) down to two or three in a graph so that the reader can visualize the data and the relationships between them. Many authors consider these graphs (two-dimensional or three-dimensional, relative to the first 2 or 3 principal components) an easy way to obtain a sort of qualitative classification. When it is possible to distinguish clusters of separate points, each relating to a gas, it is easy to think that a new unknown measure (a new point) can be classified by observing near to which cluster it will be positioned. Unfortunately, in addition to being very qualitative, this method assumes the presence of a human operator and the exploitation of his/her eyes and brain, which are powerful analysis tools but prone to subjectivity and biases. To overcome the qualitative nature of the visual inspection of PCA analysis, several classification methods have been developed that use autonomous algorithms, the output of which is not a graph but a label with the class in which the system classifies the new point.

\subsection{RGB encoding}

This is not a standard method in the literature but it is described in this section because it achieves divergent results from other studies: superior to mere classification but inferior to true quantification.

Furthermore, this method well explains an important concept for electronic noses: the information in a sensor's response signal lies in its dimensionality. In Section 1, it has already been explained that a single resistive sensor, with a dimensionless response, is almost completely devoid of selectivity. In this case, combining three responses of this type makes it evident that the selectivity of the system is sufficient for a perfect classification (at least in the case of the eight gases analyzed in this article) and even for an approximate quantification, similar to that of a litmus test.

It should be emphasized that there is no algorithm behind this method, no PCA or other variance optimization technique. The responses are simply normalized and then interpreted as the red, green, and blue channels composing a color.

\subsection{Linear discriminant analysis (LDA)}

A slightly more powerful tool that works in a similar way is LDA. This technique is used for dimensionality reduction and visualization, as is PCA, but it is also a reliable classification method. It is a linear transformation from the space of $N$-dimensions to a space with lower dimensionality $M<N$, trying to keep as much information as possible, and leaving out the noise instead. In this case, the transformation tries to minimize the variance of different groups and maximize their distance, that is, to optimize the separation. This makes it easier to divide the space into regions labeled with a given class (a gas, in our case). Unlike PCA, this algorithm can be considered a supervised method (a method in which the first set of data is used to build the model and then new data are compared to the model) and used as a classifier. In this case, the algorithm compares each new data with the model created starting from a data set used to "train" the system and classifies it by proximity (similarity) to a certain group (a gas, in our case). This method returns a label as output without the need for any interpretation, and thus, operates a true classification. As in all supervised methods, models must be tested on data sets that are completely independent of the training datasets.

\subsection{Partial least-squares discriminant analysis (PLS-DA)}

The most recent interpretation of the acronym PLS stands for "Projection to Latent Structures by means of Partial Least Squares" [12]. This technique is similar to the principal component regression (PCR, based on the PCA seen above); however, instead of finding hyperplanes of maximum variance between the response and the independent variables, it finds a linear regression model by projecting the latent variables and the observable variables into a new space [13]. Also, in this case, the new space has the same dimensionality $N$ as the original space, and therefore keeps all the information, even if it distributes it in a different (decreasing) way, trying to maximize the separation between different classes. The response variable is a numerical variable that measures the degree of belonging to a class in the $0-1$ range (total diversity-total belonging).

An advantage of PLS-DA is that it allows the transformation (similar to PCA) even on a matrix missing some elements, while previous methods could process an incomplete matrix only by eliminating individuals with missing 
variables, or by replacing the missing data with estimates. The PLS-DA, on the other hand, is able to work only on known data, even with incomplete matrices.

\subsection{Artificial neural network (ANN)}

ANNs (or just neural networks) are based on the concept of artificial neurons proposed in 1943 by McCulloch and Pitts [14]. The first electronic noses were developed using these $[15,16]$, trying to replicate the nature of a mammalian nose insofar as possible. Artificial neural networks are structures of nodes organized in layers that receive $N$ external signals on a layer of nodes, each connected to various internal nodes of the network (typically organized on several levels) with every single node processing the received signals and transmitting the result of its elaborations to subsequent levels.

Usually, neural networks comprise three layers:

1) the input (I) layer receives and processes the input signals, adapting them to the demands of the neurons of the network;

2) the hidden $(\mathrm{H})$ layer is in charge of the actual processing (and can also be structured with multiple levels of neurons);

3) the output (O) layer collects the results of the processing of the $\mathrm{H}$ layer and checks them with the expected ones.

In the case of electronic noses, a supervised learning method is used, where the system is initially "taught" through a series of labeled data. The most used learning algorithm is the vanish gradient method, which allows finding a local minimum of a function in an $\mathrm{N}$-dimensional space. The weights associated with the links between the neuronal layers are initialized to random values and the ANN is made to work with a labeled dataset.

The training of a neural network then takes place in two phases. In the first phase (forward-pass), the input data are given to the input nodes with a forward propagation of the signals through each layer of the network, with the values of the synaptic weights all fixed. In the second phase (backward-pass), the response of the network is compared with the desired output obtaining the error signal. The calculated error is propagated in the reverse direction to that of the synaptic connections. Finally, the synaptic weights are modified in order to minimize the difference between the actual output and the desired output.

\subsection{Support vector machine (SVM)}

An SVM is a supervised learning model used to analyze data both for classification and for regression. An SVM maps measurements from a first labeled data set to points in an $\mathrm{N}$-dimensional space so as to maximize the width of the gap between the categories. New measurements are then mapped into that same space and predicted to belong to a category based on the area in the space they fall into.

The algorithm works with two classes at a time, looking for a linearly separable hyperplane between them. If there is more than a hyperplane, it looks for the one that maximizes the distance between the points of the two classes it is considering (using support vectors). If there are none, it uses nonlinear mapping to bring the training data into a higher dimensionality so that two classes can always be separated by a hyperplane. This is done using a nonlinear kernel in order to obtain a nonlinear classifier without transforming the data too much.

When used for regression, it uses the same principles as for classification, with only a few minor differences. However, the main idea is similar: to minimize error, individualizing the hyperplane (a space of $N-1$ dimension) that maximizes the margin, keeping in mind that part of the error can be tolerated.

Using the SVM first as a classifier and then as a regressor (a different and independent regressor for each identified class), excellent results can be obtained both in terms of classification and quantification.

\section{Fields of application}

Unlike a single gas sensor based on metal oxide nanowires, an electronic nose is capable of detecting and distinguishing many different gases and volatile compounds. This makes it a very transversal tool, suitable for all applications where it is important to quickly understand what an atmosphere is made of, usually produced by not only a solid product or an organism but also by industrial processes and complex chains of events. An electronic nose can, for example, be used to assess the freshness of an agrifood product, carry out a prescreening by analyzing a patient's breath, or monitor the air quality in different environments (city, home, office, factory.). In this section, we will divide the articles published in the literature according to the field in which the authors tested the electronic nose, considering the most important and common 
fields: generic tests without specific application, agrifood, health, and safety fields.

\subsection{Generic application}

The group of Kolmakov proposed a "nanoscopic electronic nose" using an array of four single nanostructures [17]. Four n-type semiconducting nanostructures $\left(\mathrm{SnO}_{2}\right.$ and Ni-decorated $\mathrm{SnO}_{2}$ nanowires, $\mathrm{TiO}_{2}$ and $\mathrm{In}_{2} \mathrm{O}_{3}$ thicker nanowires) were tested toward $\mathrm{H}_{2}$ and $\mathrm{CO}$ under conditions of low pressure. The response values of three sensors $\left(\mathrm{SnO}_{2}, \mathrm{Ni}-\mathrm{SnO}_{2}\right.$, and $\left.\mathrm{TiO}_{2}\right)$ were plotted as radial plots for a qualitative classification of the two target gases.

The KAMINA platform (a linear microarray of $38 \mathrm{seg}$ ments contacted singularly) was used with $\mathrm{SnO}_{2}$ nanowires in order to fabricate an electronic nose [18]. The microarray was tested toward ethanol, isopropanol, and CO using two modalities: in the first, only the density of nanowires was varied along the array, while in the second also the working temperature. The discrimination ability (obtained qualitatively through 3D LDA graphs) increases when both parameters are varied.

The same microarray architecture was used with a constant density of pristine $\mathrm{SnO}_{2}$ nanowires, with only the temperature gradient created by four heaters on the back side of the substrate [19]. The sensors were able to detect 1 part per million ( $\mathrm{ppm})$ of CO, ethanol, isopropanol, and toluene. The system was able to classify the four gases at their lower concentration through a 3D LDA plot.
Four resistive sensors based on single nanowires $\left(\mathrm{In}_{2} \mathrm{O}_{3}, \mathrm{SnO}_{2}\right.$, and $\left.\mathrm{ZnO}\right)$ and single-walled carbon nanotubes were integrated on separate hotplates, so that their temperature could be controlled individually. Using the responses from the four sensors working at two different temperatures, the electronic nose was able to qualitatively distinguish $\mathrm{NO}_{2}, \mathrm{H}_{2}$, and ethanol and their concentrations [20]. Figure 4 shows the SEM images of the four sensors and the PCA plot obtained using only the three sensors based on metal oxide single nanowires.

The group of Moskovits described an electronic nose strategy on an array of a single $\mathrm{SnO}_{2}$ nanowire whose sensing properties were modified by surface decoration with different metal nanoparticles and different operating temperatures [21]. The sensor's selectivity was tested toward three reducing gases: $\mathrm{H}_{2}, \mathrm{CO}$, and ethylene, which were classified qualitatively through LDA plots. The discriminating ability of the e-nose was not affected by the length or diameter of the nanowires composing it.

A different system was proposed, composed of two sensors based on vertical $\mathrm{ZnO}$ nanowires with different metal oxide coatings on top of them: $\mathrm{CuO}$ and $\mathrm{SnO}_{2}$ [22]. Different response values of the two sensors toward different concentrations of $\mathrm{NO}_{2}$ and $\mathrm{H}_{2} \mathrm{~S}$ gases were plotted in radial graphs, showing different slopes, which could be used to discriminate the gases in a qualitative way.

The same architecture with vertical $\mathrm{ZnO}$ nanowires with different coatings was used also in another work of the same group [23]. In this case, the structural template consisted of vertical $\mathrm{ZnO}$ NWs coated with $\mathrm{SnO}_{2}$ on top. Different sensors were obtained sputtering very thin layers of different metals (Pt, $\mathrm{Pd}$, and $\mathrm{Au}$ ) on top of three samples, as active materials for gas sensing. The large area given by
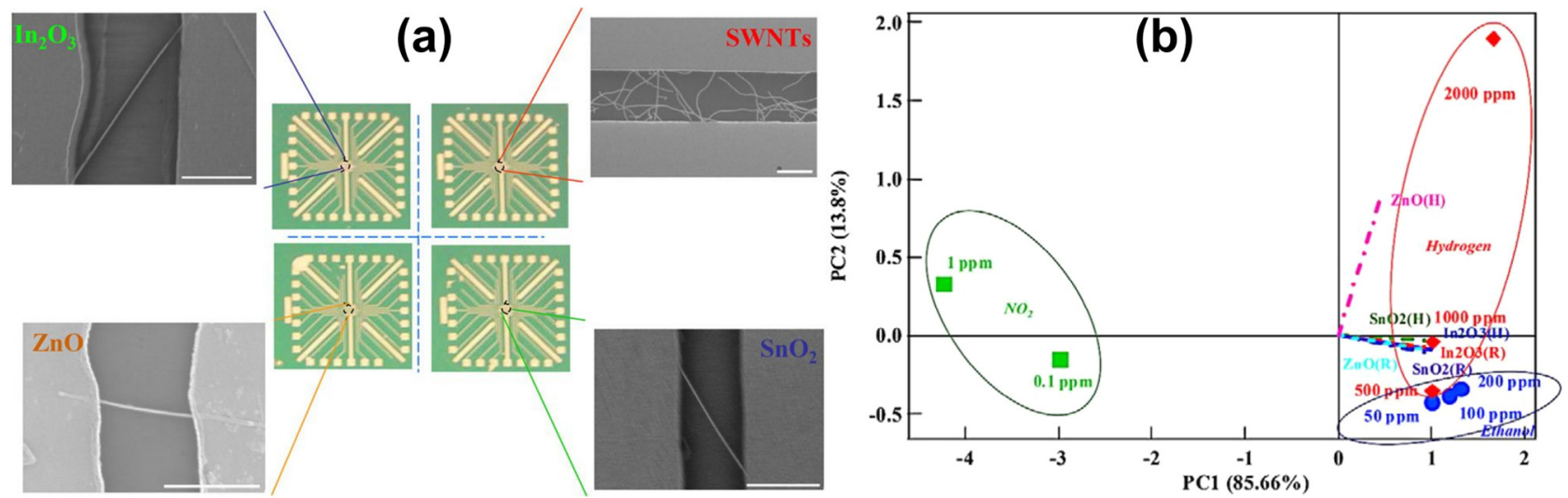

Figure 4: (a) Sensor array chip composed of four individual chemical sensors, including individual $\ln _{2} \mathrm{O}_{3}$ nanowire, $\mathrm{SnO} \mathrm{O}_{2}$ nanowire, $\mathrm{ZnO}$ nanowire, and SWNT chemical sensor chips. (b) PCA scores and loading plots of the chemical sensor array composed of only the three metal oxide single nanowires. Edited with permission from ref. [20]. 
the vertical nanowires and the catalytic effect due to the noble metals make the sensors able to detect $\mathrm{NO}_{2}$ and $\mathrm{H}_{2} \mathrm{~S}$ at room temperature. An array composed of three sensors with different decorations ( $\mathrm{Pd}, \mathrm{Pt}$, and $\mathrm{Au}$ ) was able to discriminate five different gases $\left(\mathrm{H}_{2} \mathrm{~S}, \mathrm{NO}_{2}, \mathrm{NH}_{3}, \mathrm{H}_{2}\right.$, and $\left.\mathrm{CO}\right)$ in a qualitative way (using 2D and 3D PCA plots).

As an alternative to using different materials, different surface decorations, or different working temperatures for the realization of the electronic nose, it was also proposed to take advantage of UV lighting of different wavelengths [24]. This theoretical work showed that employing a tunable UV source, the reaction on the surface of the nanowire can be tuned, achieving selectivity toward different gases. The theory behind the UV-activated gas sensing is shortly presented in terms of the energy balance when the light interacts with the surface of the nanowires.

A more traditional approach, using different nanomaterials assembled via dielectrophoresis between gold electrodes, was presented [25]. The active materials used are graphene oxide, carbon nanotubes, and $\mathrm{CuO}$ nanowires, in an array of 40 sensors. The matrix was exposed to methanol, toluene, and ammonia, and the evidence for discrimination is that the dynamic resistance of the sensors is different for different gases.

A single $\mathrm{SnO}_{2}$ nanowire was used in a KAMINA design, exploiting the decreasing diameter of the nanostructure and Pt decoration of its surface [26]. The change in resistance along the segments mirrors the change in the concentration of charge carriers and is used as a variable parameter to build the electronic nose. The microarray was able to recognize acetone and hydrogen, while it was difficult to discriminate isopropanol and $\mathrm{CO}$ in the LDA plot because of their overlap.

An array of four heterostructures made of vertical $\mathrm{ZnO}$ nanowires with different surface decorations (pristine, $\mathrm{SnO}_{2}, \mathrm{In}_{2} \mathrm{O}_{3}$, and $\mathrm{WO}_{3}$ ) was used as an electronic nose [27]. The electronic nose was able to detect $\mathrm{NO}_{2}$, $\mathrm{H}_{2} \mathrm{~S}, \mathrm{H}_{2}, \mathrm{NH}_{3}$, and $\mathrm{CO}$ at room temperature. The discrimination of the gases was obtained through a 2D PCA plot in which the only isolated cluster was that of $\mathrm{H}_{2} \mathrm{~S}$. The clusters relative to the other gases overlapped significantly, not allowing any classification.

A sensor based on $\mathrm{SnO}_{2}$ nanowires was integrated into an array to compare its performance with that of the thinfilm counterparts, testing it toward water, ethanol, and a mixture [28]. The nanowire-based sensor demonstrated performance equal to that of thin-film-based sensors, with the advantage of greater surface area/volume and flexibility.

An array of three single $\mathrm{Mg}$-doped $\operatorname{In}_{2} \mathrm{O}_{3}$ nanowires, doped with different metal $(\mathrm{Au}, \mathrm{Ag}, \mathrm{Pt})$ nanoparticles, was used to demonstrate the feasibility of an integrated electronic nose [29]. In this case, the sensors were not chemoresistors but back-gated field-effect transistors (FETs). The parameters of the transistors in the array can be used as features to obtain selectivity at room temperature, as the authors did for CO, ethanol, and hydrogen.

A different design of electronic nose with $\mathrm{ZnO}$ nanorods was realized by Ko et al. using electrodeless quartz crystal microbalances [30]. Different patterns of $\mathrm{ZnO}$ nanorods were grown on each microbalance, working as independent resonators with different frequencies. Longer nanostructures increased the quality factor of the resonators, enhancing the sensing performance of the sensor. Coating the $\mathrm{ZnO}$ nanorods with different polymers (PMMA, PVP, and PVAc), a certain selectivity was achieved, allowing for qualitatively discriminating ethanol, toluene, and gasoline in a 2D PCA plot.

Another vertical design was used to fabricate an electronic nose using different nanostructures of different materials. Six different sensors were used with different shapes (helices, rods, and zig-zags) made of different metal oxides $\left(\mathrm{TiO}_{2}, \mathrm{ITO}, \mathrm{SnO}_{2}\right.$, and $\left.\mathrm{WO}_{3}\right)$ [31]. The array of vertical sensors was used to qualitatively distinguish hydrogen, $\mathrm{CO}$, and $\mathrm{NO}_{2}$ using radar plots.

$\mathrm{Hu}$ et al. built an array composed of four single nanowires, trying to exploit the different selectivities of the most diverse materials, namely a metal (Pd), two polymers (PPy and PANI), and a semiconductor ( $\mathrm{ZnO}$ ) [32]. Four target gases were selected to test the performance of the array: hydrogen, methanol, $\mathrm{CO}$, and $\mathrm{NO}_{2}$. The authors were able to qualitatively discriminate the four gases, also using blinded experiments where new measurements were compared in the PCA plot with the calibration points, thus also providing a quantitative estimation of the gas concentration. As can be seen in Figure 5, the four sensors were quite selective toward the four tested gases and this was reflected in the three-dimensional PCA plot. Figure $5 \mathrm{c}$ compares the real composition of the tested gases with that estimated by the sensing system.

$\mathrm{An}$ array of three different on-chip grown $\mathrm{ZnO}$ and $\mathrm{CuO}$ nanowires was used as a prototypal electronic nose [33]. In practice, by growing $\mathrm{ZnO}$ and $\mathrm{CuO}$ nanowires directly from the electrodes, three sensors were made that exploit different junctions: $\mathrm{ZnO}-\mathrm{ZnO}, \mathrm{ZnO}-\mathrm{CuO}$, and $\mathrm{CuO}-\mathrm{CuO}$, as shown in Figure 6a. Using three sensors of the pristine metal oxides, three decorated with Pd nanoparticles and three with $\mathrm{Ag}$ nanoparticles, nine sensors were combined ( 3 junctions $\times 3$ surface decorations). The sensors were able to qualitatively distinguish $\mathrm{H}_{2}$, $\mathrm{CO}$, and $\mathrm{NO}_{2}$ in an LDA plot.

A more traditional approach, using different metal oxides $\left(\mathrm{VO}_{x}, \mathrm{MnO}_{x}, \mathrm{WO}_{x}\right.$, and $\left.\mathrm{NiO}_{x}\right)$ deposited on finger 


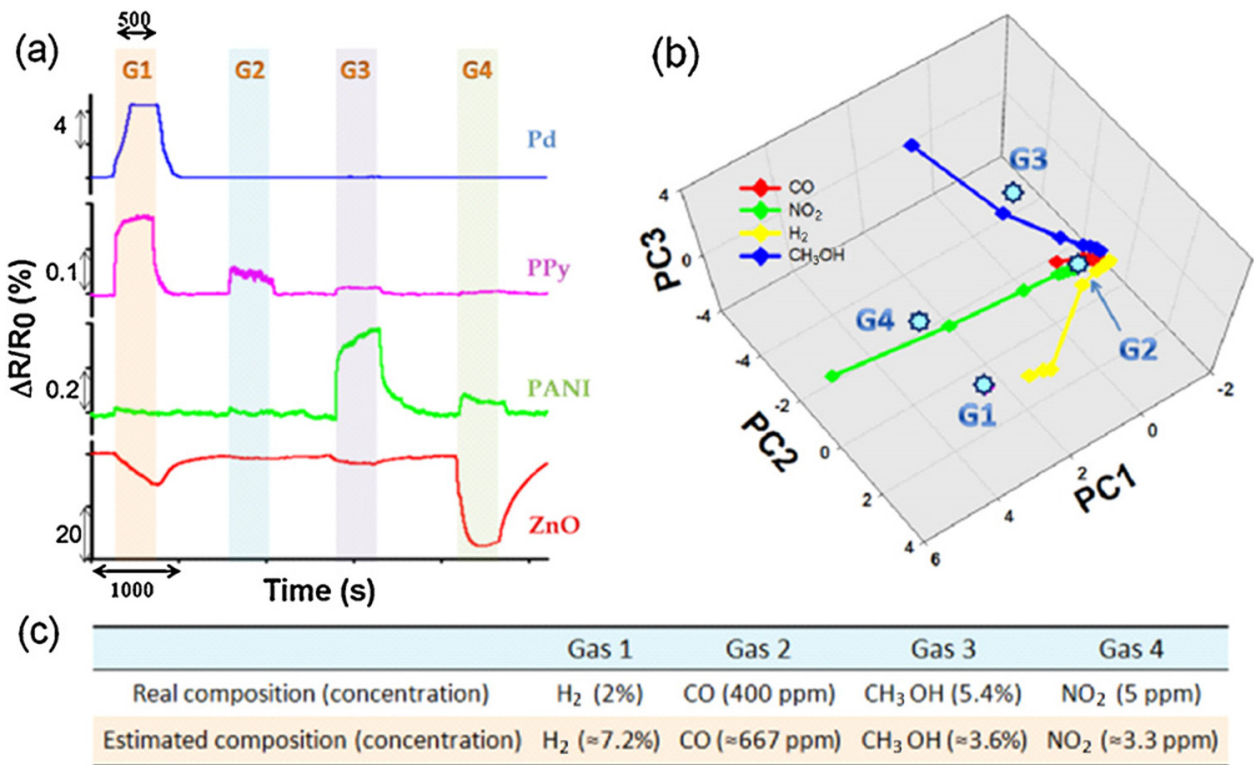

Figure 5: Real-time sensing signals and the corresponding PCA plot. (a) Dynamic percentage response (change in resistance divided by the base resistance) collected from the four sensors during four response-recovery cycles. (b) 3D PCA plot including training points (colored points connected by lines) and test points (four teal octagons labeled G1-G4); (c) comparison between the real gases injected and the estimates from the sensing system. Modified with permission from ref. [32].

electrodes [34]. The semiconducting nanostructures were assembled via dielectrophoresis onto electrode arrays and then packaged for easy testing. Looking at the fractional resistance that was affected by the presence of ethanol, acetone, methanol, and ammonia, the authors were able to discriminate between ethanol and ammonia. They are confident that with the help of a machine learning algorithm, this setup would be able to achieve real selectivity.

Thicker surface decoration was implemented on $\mathrm{ZnO}$ nanowires, realizing almost a core-shell situation [35]. After atomic layer deposition of thin layers $(5 \mathrm{~nm})$ of $\mathrm{Al}_{2} \mathrm{O}_{3}$ and $\mathrm{TiO}_{2}$, two types of core-shell nanostructures were obtained: $\mathrm{ZnO}-\mathrm{ZnAl}_{2} \mathrm{O}_{4}$ and $\mathrm{ZnO}-\mathrm{Zn}_{2} \mathrm{TiO}_{4}$ nanowires, used as sensing elements at room temperature under UV illumination. Using an array comprising pristine $\mathrm{ZnO}$ nanowires also, the authors were able to qualitatively discriminate $\mathrm{O}_{2}, \mathrm{O}_{3}$, $\mathrm{CO}$, and $\mathrm{NO}_{2}$ using bar plots and a 3D PCA plot.

A network of potassium titanate nanowires was used as a chemiresistor to detect acetone and ethanol at room temperature [36]. The network was segmented into 11 different sensors, which are different because of the intrinsic variation of the density of the nanowires. Combining the response values of the 11 sensors and processing them with LDA, different clusters were found for
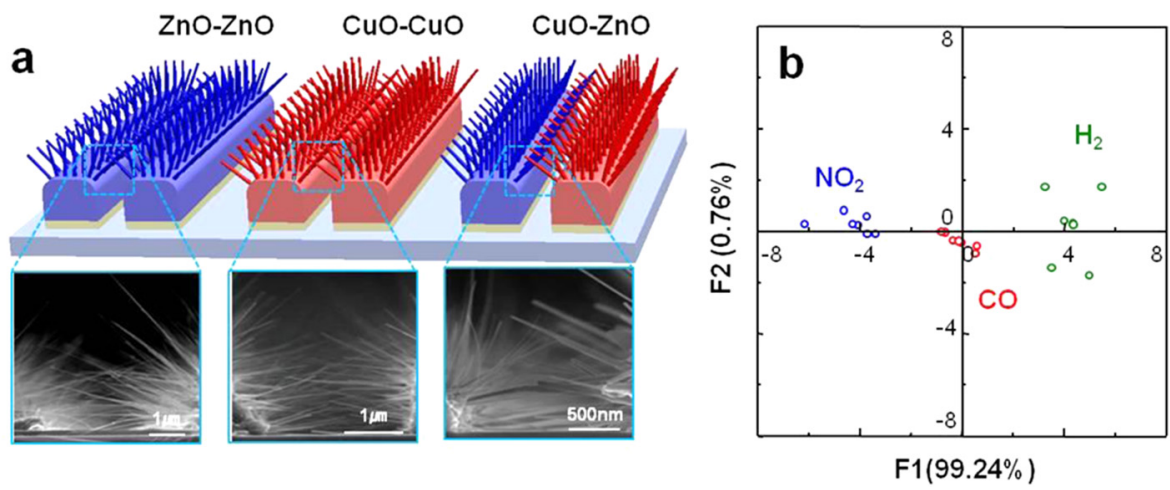

Figure 6: (a) Schematic representation of the crossed-nanowire junction array and corresponding SEM images. (b) LDA analysis classifying the points corresponding to the various gases at a $95 \%$ confidence level. Reprinted with permission from ref. [33]. 
acetone and ethanol, proving a certain qualitative classification from the system.

The role of metal oxides is different in the work of Song and Choi, who use polymeric nanowires surface decorated with three different catalysts as sensors: Ag, $\mathrm{CuO}$, and $\mathrm{Mn}_{2} \mathrm{O}_{3}$ [37]. Four sensors (including pristine PANI nanowires) were used to obtain an array and achieve a qualitative selectivity. The sensing system was tested with ascorbic acid, dopamine, and $\mathrm{H}_{2} \mathrm{O}_{2}$ in liquid as an electronic tongue but could also be operated with gases, as an electronic nose. The different analytes and their mixtures were discriminated qualitatively and semiquantitatively through two-dimensional PCA plots.

Polycrystalline $\mathrm{NiO}$ nanowires were used as a chemiresistor to demonstrate that selectivity can be tuned toward different target gas by changing the working temperature of the sensor [38]. The sensor response to hydrogen is larger at $200^{\circ} \mathrm{C}$ and decreases as the temperature increases, while the response to ethanol increases with temperature and reaches its maximum at $400^{\circ} \mathrm{C}$. In this way, by varying the temperature of the sensor, it is possible to set its selectivity toward one of the target gases.

An electronic nose based on different materials and different shapes was proposed as very sensitive system to detect gases and volatiles [39]. The sensing system was formed by three metal oxides $\left(\mathrm{WO}_{3}, \mathrm{SnO}_{2}\right.$, and $\left.\mathrm{In}_{2} \mathrm{O}_{3}\right)$ in three versions: pristine thin films, Au-decorated thin films, and vertical nanowires, thus obtaining a $3 \times 3$ array. The classification is shown qualitatively by means of 2D PCA plots. Using only the thin films, the electronic nose is able to discriminate $\mathrm{NH}_{3}$ and $\mathrm{H}_{2} \mathrm{~S}$, while adding the nanowires it can also distinguish NO. On the other hand, it cannot distinguish acetone, benzene, $\mathrm{CO}$, and ethanol.

A different approach consisted of using a single $\mathrm{SnO}_{2}$ nanobelt suspended between two electrodes, acting as a FET [40]. Different FET parameters were extracted $\left(I_{\mathrm{ON}}\right.$, mobility, threshold voltage, subthreshold swing) and used as features to be processed by LDA. The two-dimensional LDA plot shows a qualitative classification of $\mathrm{NO}, \mathrm{NO}_{2}$, and $\mathrm{H}_{2} \mathrm{~S}$. After this classification, a possible quantification is proposed, comparing the measurement with the calibration ones.

The on-chip growth of $\mathrm{SnO}_{2}$ NWs was used to manufacture an array of self-heated gas sensors in order to simplify the fabrication process and avoid the need for an external heater, reducing the power consumption [41]. Tuning the sensor power, different response values can be obtained, which vary for each gas, and can therefore be considered as fingerprints.

In addition to the intrinsic selectivity of the sensor toward $\mathrm{NO}_{2}$, the self-heated system could qualitatively discriminate $\mathrm{H}_{2}, \mathrm{NH}_{3}, \mathrm{H}_{2} \mathrm{~S}$, and $\mathrm{C}_{2} \mathrm{H}_{5} \mathrm{OH}$.
A chemoresistive electronic nose based on pristine and $\mathrm{Au}$-decorated $\mathrm{SnO}_{2}$ and $\mathrm{WO}_{3}$ nanowires was fabricated by electron-beam evaporation at a glancing angle [42]. The back-heated $2 \times 2$ array ( 2 materials $\times 2$ surface decorations) has a sub-ppm detection limit for NO and $\mathrm{NH}_{3}$ in $80 \%$ relative humidity (RH). A two-dimensional PCA plot demonstrated that the electronic nose is able to well distinguish $\mathrm{NO}$ and $\mathrm{NH}_{3}$, while the other gases $\left(\mathrm{C}_{2} \mathrm{H}_{5} \mathrm{OH}, \mathrm{CO}, \mathrm{C}_{7} \mathrm{H}_{8}, \mathrm{C}_{6} \mathrm{H}_{6}\right.$, and $\left.\mathrm{CH}_{3} \mathrm{COCH}_{3}\right)$ are too overlapped. The position in the PCA graph of the points relative to $\mathrm{NO}$ and $\mathrm{NH}_{3}$ shows that a quantitative analysis of these two gases would probably also be possible.

Nanowires of different materials have been grown on the same chip exploiting the presence of different membranes with integrated heaters [43]. The ability to locally heat the chip allowed to grow $\mathrm{SnO}_{2}$, $\mathrm{WO}_{3}$, and Ge nanowires on different sensors of the same chip and later to optimize the working temperature of each sensor. The electronic nose was able to qualitatively distinguish $\mathrm{CO}$, $\mathrm{NO}_{2}$, and $\mathrm{RH}$ in a 2D PCA plot.

A sensor made of $\mathrm{NiO}$ nanowires was made working at different temperatures in order to simulate a temperature gradient and a virtual electronic nose [44]. The fingerprints of seven reducing gases $\left(\mathrm{H}_{2} \mathrm{~S}\right.$, ethanol, $\mathrm{H}_{2}, \mathrm{CO}$, $\mathrm{NH}_{3}, \mathrm{CO}_{2}$, and $\mathrm{LPG}$ ) were each combined in a $5 \mathrm{D}$ point and processed by machine learning. The shape of the fingerprints is very similar even after changing the gas concentration. Using SVMs, the system was able to achieve perfect classification and very good quantification $(<15 \%$ average error).

An array of four sensors based on vertical polycrystalline $\mathrm{SnO}_{2}$ nanotubes decorated with Pt was proposed as an ultra-lower power electronic nose [45]. The four sensors were top-coated with different materials ( $\mathrm{Au}$, $\mathrm{Pt}, \mathrm{Ni}$, ITO) in order to change their intrinsic selectivities. The sensor array was tested with $\mathrm{RH}, \mathrm{NO}_{2}$, benzene, and $\mathrm{H}_{2}$. The 3D LQV plots, similar to PCA plots, showed that the points are well dispersed, allowing to classify the gases and probably even to estimate the concentrations.

Three sensors based on $\mathrm{SnO}_{2}, \mathrm{WO}_{3}$, and Ge nanowires were integrated on the same chip, thanks to localized growth driven by local heating [46]. Using different membranes with integrated heaters (Figure 7a), the nanowires were grown directly on the patterned electrodes by chemical vapor deposition (CVD). The responses from the three materials were combined and analyzed through PCA. Figure $7 \mathrm{~b}$ shows a clear qualitative classification of humidity, $\mathrm{CO}$, and $\mathrm{NO}_{2}$ with well-isolated clusters of points for each gas.

A visual sensor (a kind of electronic nose that works like a litmus paper) was manufactured with very simple 

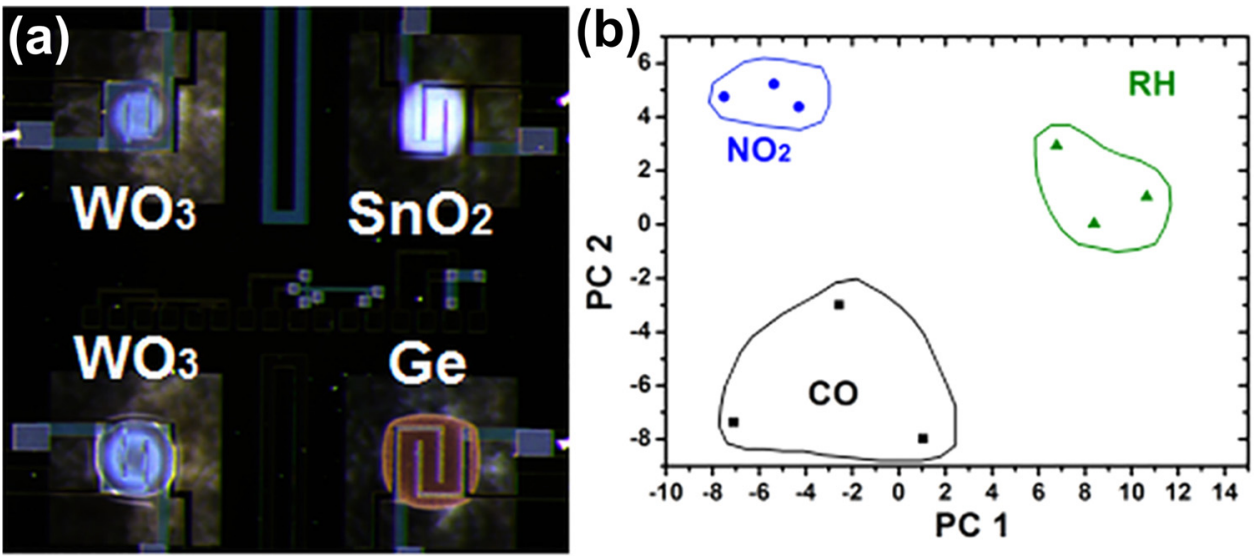

Figure 7: (a) Optical images of the blue tungsten oxide $\mathrm{WO}_{3-x} \mathrm{NWs}$, the white $\mathrm{SnO}_{2} \mathrm{NW}$ deposit, and brown coating of Ge. (b) PCA from SnO $\mathrm{WO}_{3}$, and $\mathrm{GeNW}$-based gas sensors showing clustered $\mathrm{CO}, \mathrm{NO}_{2}$, and $\mathrm{RH}$ points. Reprinted with permission from ref. [46].

processing of signals from sensors based on $\mathrm{NiO}$ nanowires [47]. The response at each working temperature was just normalized to a $0-255$ range in order to be encoded as one of the three channels in the color space. The combination of the three channels allowed us to easily recognize any of the eight tested gases $\left(\mathrm{NH}_{3}\right.$, LPG, $\mathrm{H}_{2} \mathrm{~S}$, ethanol, $\mathrm{H}_{2}, \mathrm{NO}_{2}$, $\mathrm{CO}$, and $\mathrm{CO}_{2}$ ). A renormalization of every single gas also allowed us to reach a qualitative estimate of the gas concentration.

Similar to Sysoev's work [26], but using a temporal rather than spatial thermal gradient, an electronic nose was made using a single $\mathrm{SnO}_{2}$ nanowire [48]. The responses of the sensor at five different temperatures were combined to greatly increase the intrinsic poor selectivity of the resistive sensor. Using an SVM, the nanometric electronic nose achieved a classification of $94.3 \%$ and a good estimate of the concentrations (18.4\%) for ethanol, $\mathrm{H}_{2}$, CO, acetone, $\mathrm{NH}_{3}$, and toluene. There was sometimes confusion with $\mathrm{NO}_{2}$ at low concentrations.

An electronic nose was built that exploits the intrinsic inhomogeneity of a network of $\mathrm{ZnO}$ nanorods deposited on a multielectrode chip [49]. The system was able to detect isopropanol, ethanol, and butanol at sub-ppm concentrations, and separate them well in a 2D LDA plot, as shown in Figure 8. Using the Mahalanobis distance, the authors demonstrated that the separation of points at higher concentrations is greater.

A sensor based on $\mathrm{SnO}_{2}$ nanowires grown directly from the metal electrodes and then decorated with $\mathrm{Pt}$ nanoparticles by radiolysis was used as an electronic nose by using it at different working temperatures [50]. The thermal fingerprints for each gas (benzene, acetone, $\mathrm{H}_{2}$, toluene, and ethanol) were shown as a function of the gas concentration, and a 3D PCA plot showed that the gas clusters are well separated. Using an SVM, it was possible to obtain a good estimate of the concentration of each gas (approximately 14\%).

A sensor based on carbon-doped $\mathrm{SnO}_{2}$ nanowires was operated in a low range of temperatures in order to use it as an electronic nose [51]. At each temperature, the sensor showed a different intrinsic traditional selectivity, while the combination of the five response values resulted in wellseparated clusters in a uniform manifold approximation and projection (UMAP) for the gas tested (ethanol, $\mathrm{H}_{2}$, CO, acetone, $\mathrm{NH}_{3}$, and toluene). Several classification methods were tested, most of which gave a perfect accuracy of $100 \%$. The use of an SVM gave good estimates for all the gas concentrations, with an error decreasing as the concentration increased.

In a similar approach, a self-heating sensor made of Ag-decorated $\mathrm{SnO}_{2}$ nanowires was heated at three

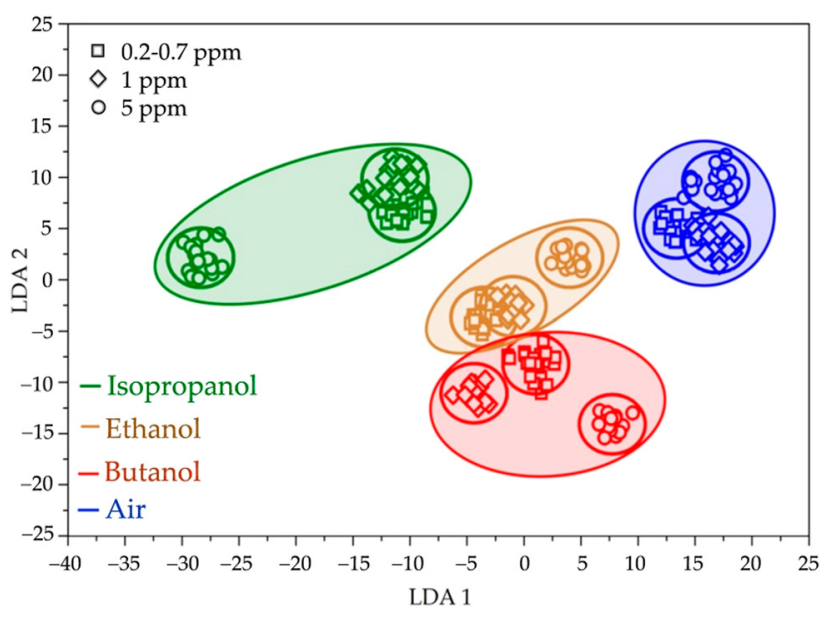

Figure 8: LDA plot showing that the electronic nose can recognize the different gases at different concentrations, from sub-ppm to $5 \mathrm{ppm}$. Reprinted with permission from ref. [49]. 
different levels of power, and the responses obtained were combined to be used as an electronic nose [52]. The nanowires were grown directly from the side of the sensor electrodes and then decorated with $\mathrm{Ag}$ nanoparticles by sputtering. The sensor was able to detect $\mathrm{H}_{2} \mathrm{~S}, \mathrm{H}_{2}$, $\mathrm{NH}_{3}$, ethanol, and acetone at sub-ppm concentrations and well separated in a 3D PCA plot. Using an SVM, a good quantification of the gas concentration was achieved. Such an approach could transform a single resistive sensor into a miniaturized electronic nose.

A similar approach using edge-grown $\mathrm{SnO}_{2}$ nanowires was used to fabricate four sensors to be used in parallel, in a spatial thermal gradient instead of temporal [53]. The four on-chip sensors are patterned at an increasing distance (decreasing temperature) from a heater, in the same lithography. The four response signals are collected simultaneously and processed together. A series of radar plots showed different shapes for methanol, IPA, ethanol, $\mathrm{NH}_{3}, \mathrm{H}_{2} \mathrm{~S}$, and $\mathrm{H}_{2}$.

In a similar way, two chips with $\mathrm{SnO}_{2}$ nanowires, one decorated with $\mathrm{Ag}$ and one with Pt nanoparticles, were used together to build up a more sensitive electronic nose [54]. The responses from the eight sensors were combined and processed with machine learning algorithms. In a first step, a t-distributed stochastic neighbor embedding (t-SNE) was used to show the relationships between the gas clusters, showing a good separation of the tested gases (acetone, ethanol, $\mathrm{H}_{2}, \mathrm{H}_{2} \mathrm{~S}$, and $\mathrm{NH}_{3}$ ). In a successive step, the gas concentration was estimated by an SVM, obtaining an average error of $18.3 \%$.

An electronic nose based on $\mathrm{ZnO}$ nanowire chemoresistors was realized decorating different sensors with different sensitizers, namely $\mathrm{Ni}, \mathrm{Co}, \mathrm{Mg}$, and $\mathrm{Fe}$ [55]. Showing the response of the different sensors (pristine $\mathrm{ZnO}$ and sensitized ones) toward $\mathrm{H}_{2} \mathrm{~S}, \mathrm{NO}_{2}, \mathrm{NH}_{3}$, and $\mathrm{CO}$, the authors showed that the array has the potential to act as an electronic nose.

Two electronic noses each based on a forest of nanowires of a single material $\left(\mathrm{SnO}_{2}\right.$ and $\mathrm{ZnO}$, respectively) working at different temperatures were compared by measuring different gases (acetone, ammonia, ethanol, hydrogen, nitrogen dioxide). Under the same conditions (similar nanowire morphology, same working temperatures, and gas concentrations), the $\mathrm{SnO}_{2}$-based device proved to be better, perfectly classifying all gases and quantifying them with an error of less than 10 ppm [56].

Kanaparthi and Singh tested a single sensor based on $\mathrm{ZnO}$ nanostructures, operating it at $250^{\circ} \mathrm{C}$, to detect $\mathrm{NH}_{3}$, $\mathrm{CO}_{2}$, and $\mathrm{H}_{2} \mathrm{~S}$. When the sensor detected the presence of gas, it was also tested at 300 and $350^{\circ} \mathrm{C}$. The three responses were used, together with simple ternary logic, to classify the measured gas by random forest with an accuracy of 99.8\% [57]. Some characteristics and parameters of the electronic noses analyzed in this section are compared in Table 1.

\subsection{Agrifood}

An individual $\mathrm{SnO}_{2}$ nanobelt was contacted by multiple electrodes in order to obtain ten segments acting as an array of resistive sensors, some of which were decorated with Pd nanoparticles [58]. Due to the decreasing width and the localized Pd decoration, the sensors had different sensitivities and acted as an electronic nose. In a first step, the system proved to be able to distinguish toluene, isopropanol, ethanol, and CO. Then, as can be seen in Figure 9, radar charts and an LDA plot showed that the electronic nose was able to qualitatively distinguish the aroma of different alcoholic beverages: glühwein, champagne, vermouth, and brandy, all diluted up to $10 \%$ ethanol content.

$\mathrm{SnO}_{2}$ nanowires were integrated into a commercial electronic nose (EOS835 from SACMI, Imola, Italy) in order to enhance its performance [59]. In the first phase, the electronic nose was tested on individual gases, namely CO, ethanol, $\mathrm{NH}_{3}$, and $\mathrm{H}_{2} \mathrm{~S}$, and the results are shown in a radar plot. Subsequently, the electronic nose was used to assess the quality of green coffee beans, distinguishing moldcontaminated samples from uncontaminated ones.

The same commercial electronic nose was equipped with two (on six) sensors based on $\mathrm{SnO}_{2}$ nanowires in order to investigate coffee from different origins (India, Indonesia, Santos, Honduras, Nicaragua) roasted following four different programs and ground $[60,61]$. A two-dimensional PCA chart showed that the origin of the coffee is more important than the roasting method in generating the aroma of the coffee.

A commercial electronic nose (EOS507, SACMI, Imola, Italy) was equipped also with $\mathrm{SnO}_{2}$ nanowires and then used for a rapid assessment of tomato paste and vegetable soups, in some cases artificially contaminated with yeasts and bacteria [62]. After $24 \mathrm{~h}$ of inoculation, the electronic nose was able to correctly classify tomato samples spoiled with $C$. milleri yeast and vegetable soup samples contaminated with E. hormaechei and E. coli in 98.9 and $100 \%$ of cases, respectively.

An $\alpha$-FOX electronic nose (Alpha MOS, Toulouse, France) using tin oxide, chromium titanium oxide, and tungsten oxide sensors with different geometries were used to distinguish five different cultivars of garlic. The odor profiles of the fresh garlic scapes (Sureño, Castaño, 


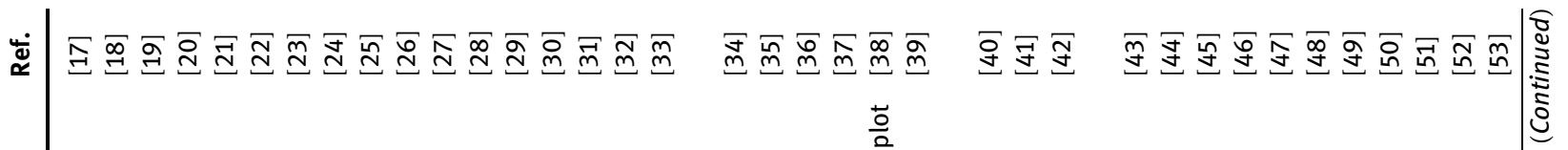

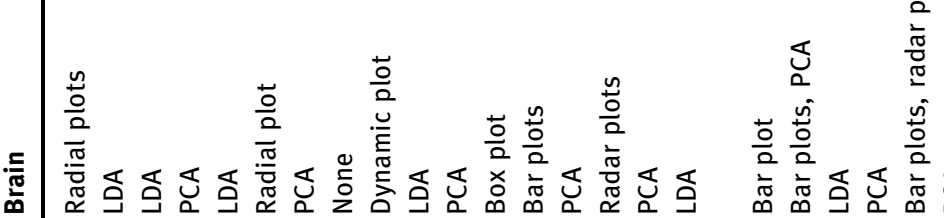

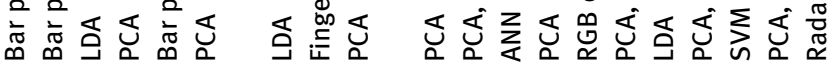

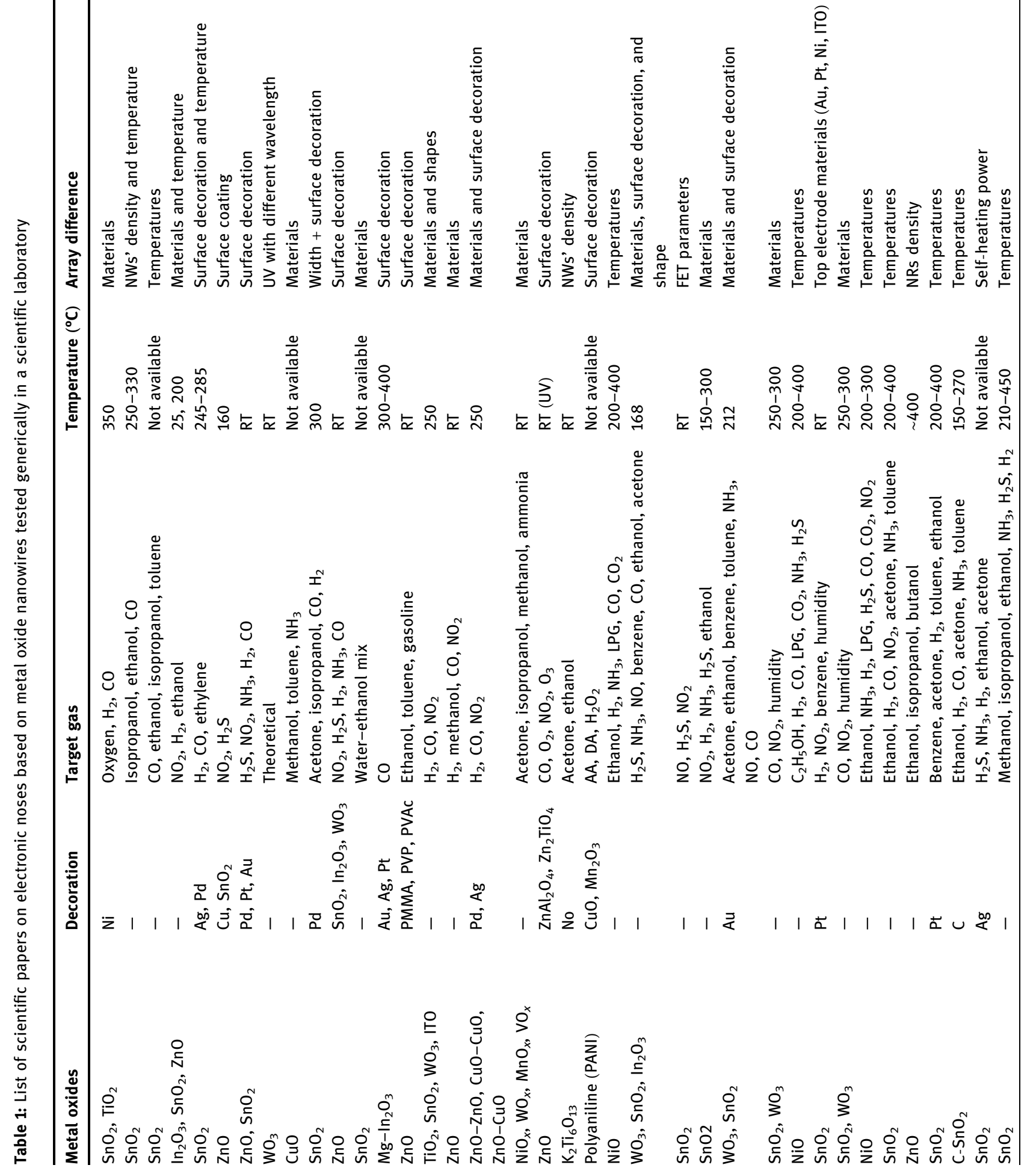


Gostoso, Fuego, and Morado) were expected to be different because of different amounts of allicins and sulfide compounds. LDA was used to analyze the garlic scapes, proving that the electronic nose is able to distinguish the different cultivars with a correct classification of $53.3 \%$ [63].

An e-nose system using eight metal oxide sensors by Parallax Engineering Inc. (Long Beach, CA, USA) was used to measure different climacteric fruits and assess their ripeness. The results were first visually inspected in the form of radar graphs, showing a significant difference between the odor prints of guava, banana, and orange samples. The responses of the sensors were then combined and analyzed with the PCA, managing to qualitatively distinguish the three fruits [64].

Three sensors (on six) of a commercial electronic nose EOS835 were replaced with resistive devices based on $\mathrm{SnO}_{2}$ and $\mathrm{ZnO}$ nanowires, and the instrument was used to assess the quality of grated Parmigiano Reggiano (PR) cheese [65]. Different kinds of crust and pulp were mixed with different ratios, and the electronic nose was able to qualitatively classify the pure-pulp samples from those with 5 and $10 \%$ of the crust, through a two-dimensional PCA plot.

The results from a commercial electronic nose, a panel of nine expert panelists, and a gas chromatograph were compared analyzing 25 samples of PR [66].

The EN, based on an array of six metal oxides gas sensors (three of which in the form of nanowires), was used to evaluate the quality of grated PR samples. It was able to qualitatively discriminate between degraded and nondegraded samples (Figure 10a) and recognize the degree of seasoning (Figure 10b), demonstrating that such a fast and sensitive tool would help in the quality control of food products.

Two conductometric gas sensors, based on $\mathrm{ZnO}$ and $\mathrm{SnO}_{2}$ nanowires grown on alumina substrates, were fabricated and used together to investigate samples of grated PR with different crust contents (from 0 to 100\%) [67]. The sensing system was able to qualitatively distinguish three groups of points in a PCA plot, relating to samples with 20,50 , and $100 \%$ crust content.

The S3 device from the SENSOR laboratory in Brescia was tested by assessing the quality of grated PR and comparing it with the opinions of a panel of experts [68]. The instrument isolated the samples evaluated as "bad" by the panelist from those evaluated as "good" or "flat", proving capable of performing a quality prescreening.

The same instrument was tested, in parallel with a spectrocolorimeter, to investigate the ripening (from 11 to 36 months) of grated PR [69]. A PCA plot shows that the 
(a)

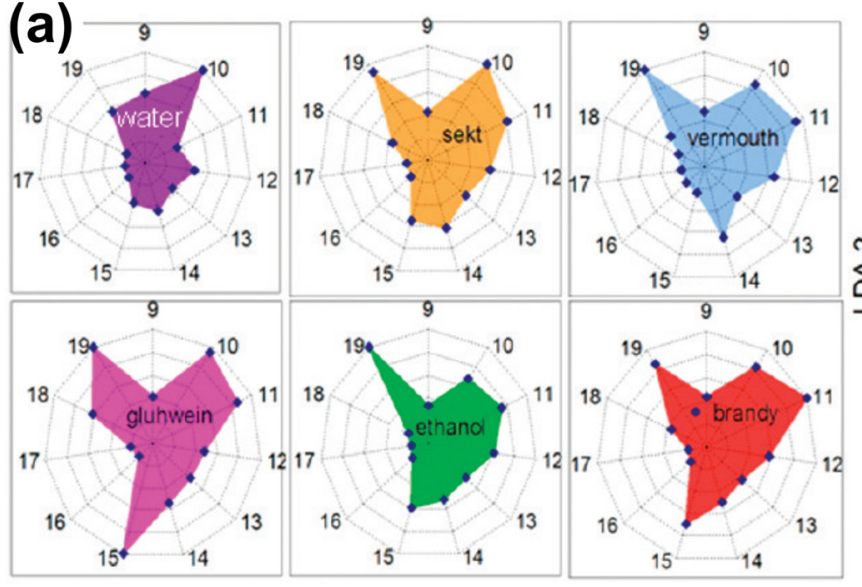

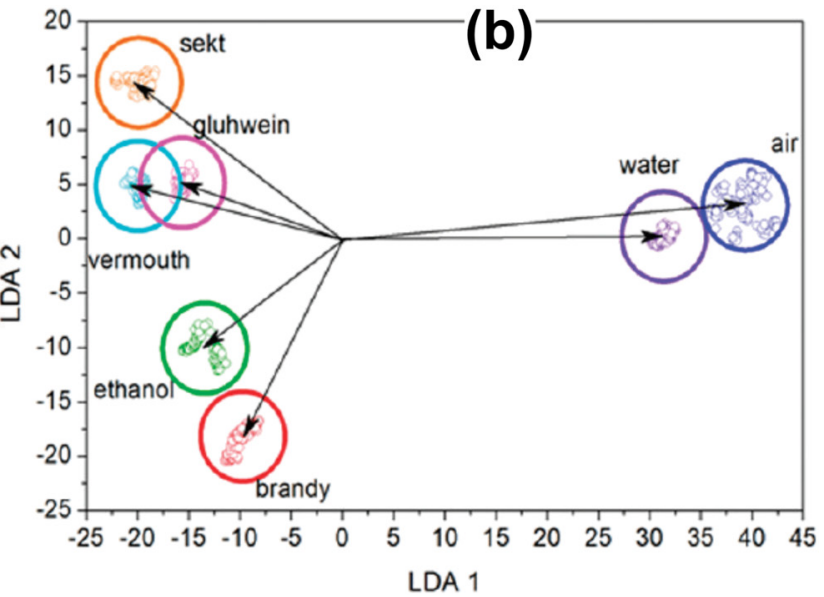

Figure 9: (a) Polar plots with the responses of the sensors in the array to the aroma of various alcoholic beverages. (b) Corresponding LDA plot of the sensor array to the beverages aromas. Reprinted with permission from ref. [58].
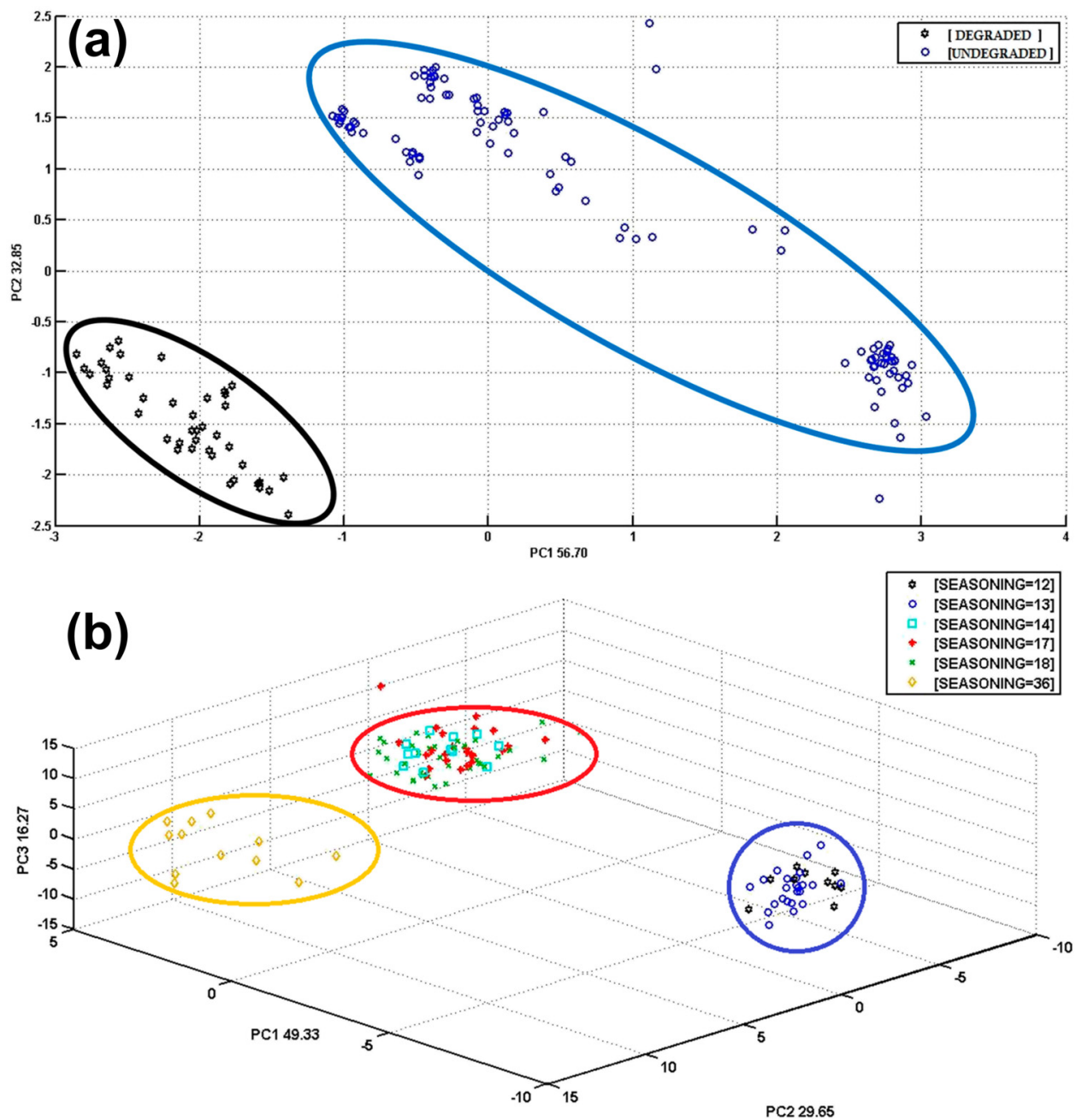

Figure 10: (a) PCA plot of degraded and undegraded cheese samples in black and blue, respectively. (b) PCA of cheese samples with different ripening times (in months). Edited with permission from ref. [66]. 
different ripening categories are quite separate, except the 24 and 30 month ones, which are overlapping.

An electronic nose that also uses MO nanowires was used to identify possible counterfeits of PR around the world [70]. Several samples of PR from different producers and several samples from European and US competitors were tested. Gas chromatography showed that six volatile compounds were sufficient to discriminate against USA or European competitors (EC) of PR. Using the response and response time of selected sensors as features for PLS, the electronic nose was able to distinguish the original PR from competitors with an $80 \%$ correct classification. A PLS score plot is shown in Figure 11, demonstrating the classification of PR, European, and USA competitors.

Three nanowire-based gas sensors were used in an electronic nose composed of six sensors in order to recognize different characteristics of grated PR [71]. The classification from PLS-DA and ANNs was evaluated and compared. The electronic nose was used to estimate both the seasoning (12 or 24 months), the rind working process, and the percentage of rind present in the grated product. The classification of the seasoning was perfect for ANN and correct in $94.7 \%$ of cases for PLS-DA. The classification of the rind working process was perfect in all cases but the 24-month samples with PLS-DA gave a
$79 \%$ correct label. The classification of the rind percentage ranged from 58.8 and $100 \%$.

An electronic nose with three sensors based on MO nanowires (out of a total of eight MO sensors) was used to detect the presence of Campylobacter jejuni, for a potential application in the agrifood field [72]. Since the bacteria consume some molecules and their metabolism produces other molecules, their presence can be detected by the headspace. The electronic nose was able to qualitatively follow the bacteria growth and concentration increase in a PCA plot.

A low-power electronic nose using $\mathrm{SnO}_{2}, \mathrm{CuO}$, and $\mathrm{WO}_{3}$ nanowires was used to detect different food preservatives (ethanol, nitrogen dioxide, and ozone) [73]. The three gases overlap on the PCA plot, showing a poor qualitative classification. The integration of the nanowires on micro hotplates allows one to foresee the use of pulsed temperature operation.

The S3 electronic nose developed by the group of Brescia was used to assess some characteristics of PR [74]. This work is meant to generalize the results obtained in ref. [71]. Using an array of different sensors, the authors identified several different features from each sensor signal, then verified which were the most informative and used them to train an ANN. This process in three

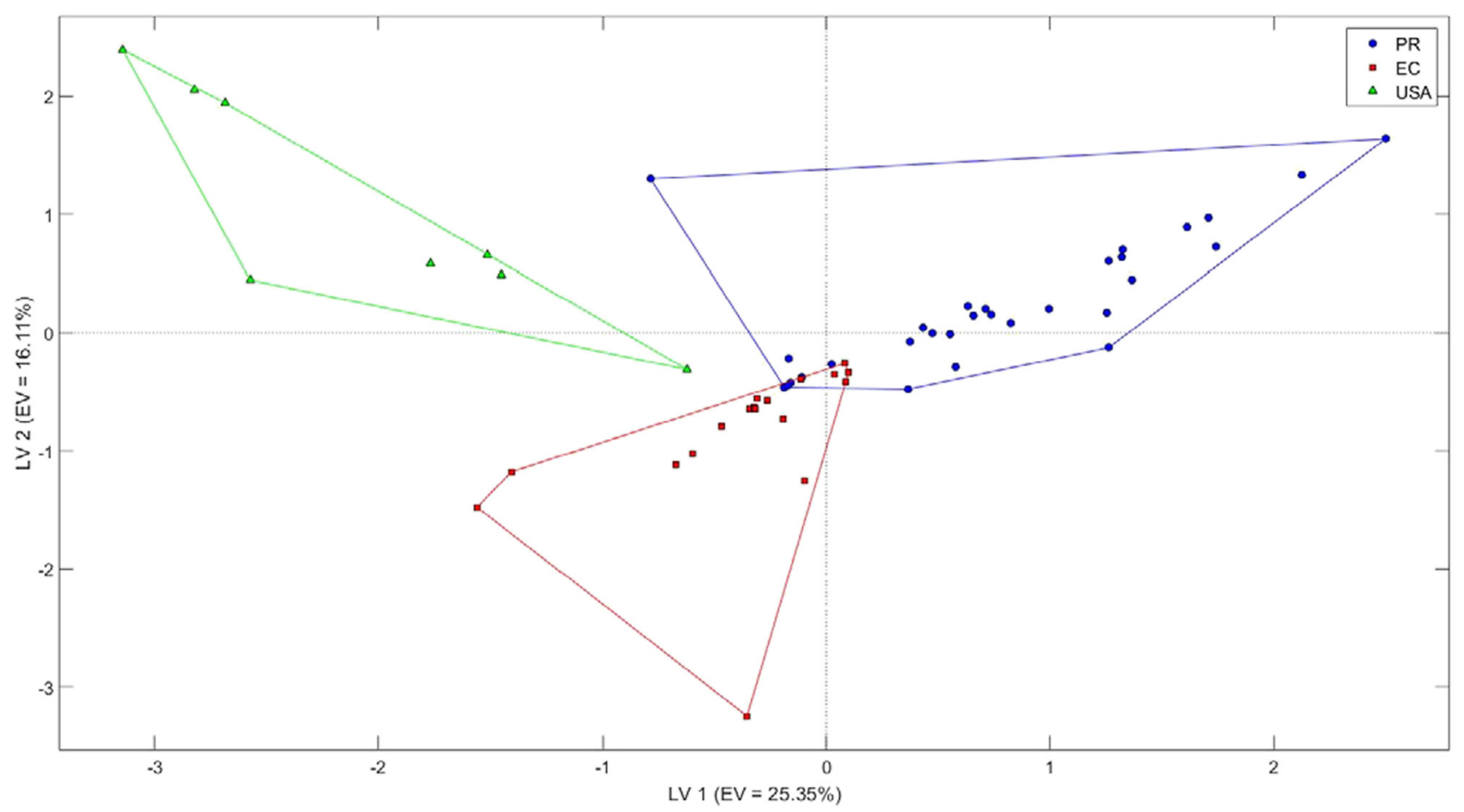

Figure 11: PLS score plot showing different cheeses. PR is represented by blue circles, EC by red squares, and US competitors (USA) by green triangles. Reprinted with permission from ref. [70]. 
steps was repeated for each classification (seasoning, rind working process, rind percentage) in order to optimize it. By choosing the best materials and features, a classification accuracy between 88 and 100\% was found. Figure 12 shows four of the many features selected to train the ANN and then to test the electronic nose.

A single $\mathrm{SnO}_{2}$ nanowire was used at three different temperatures in order to mimic an electronic nose. The responses of the single-nanowire chemiresistor at 200, 250 , and $300^{\circ} \mathrm{C}$ were combined and analyzed with principal component analysis. The system proved capable of assessing the freshness of rainbow trout fish according to their total viable count measurement [75]. The PCA graph in Figure 13 where the freshness of the fish is indicated by the color of the points shows a curve indicating the degradation of the fish.

An electronic nose consisting of a single $\mathrm{SnO}_{2}$ semiconductor nanowire, used at different temperatures $\left(200-360^{\circ} \mathrm{C}\right)$, was used to recognize the degradation state of pig and marble trout samples. Using as features the response of the resistive sensor at five different working temperatures, the device was able to recognize the type of sample (meat or fish) in $95.2 \%$ of cases and to evaluate its freshness in $90.5 \%$ of cases [76].

(a)
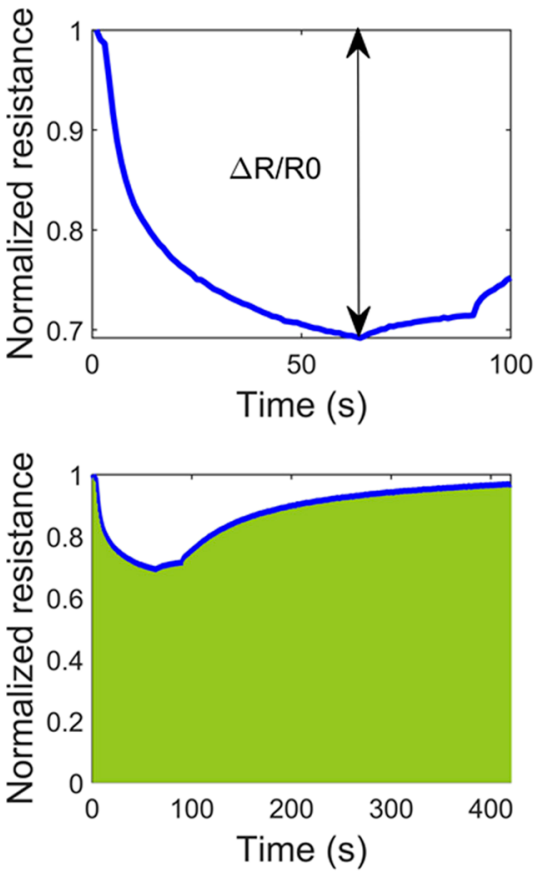

(c)
An electronic nose composed of four commercial sensors (MQ-138, MQ-135, MQ-3, and TGS 2602) based on $\mathrm{SnO}_{2}$ was used to recognize whitefly infestation in tomato plants. The electronic nose was able to distinguish healthy plants from stressed ones by means of HCA and PCA [77]. Using gas chromatography-mass spectrometry, the authors found that only infested plants produced 2-nonanol and $n$-hexadecanoic acid, which have known antiparasitic properties against nematodes. This suggests that they are emitted by plants in response to the attack of the whitefly and that the sensors can detect this effect.

An array of six commercial $\mathrm{SnO}_{2}$-based gas sensors were used to detect the presence of $E$. coli in chicken samples [78]. Six statistical features (mean, kurtosis, median, standard derivation, skewness, and variance) were extracted from the measurement of each sensor. Using a random forest, the electronic nose was able to identify fresh and contaminated samples with an accuracy of 99.2 and $98.4 \%$, respectively.

Six composite sensors, based on $\mathrm{SiO}_{2}$ nanofibers: $\mathrm{In}_{2} \mathrm{O}_{3}$, $\mathrm{SiO}_{2}: \mathrm{ZnO}$ and $\mathrm{SiO}_{2}$ modified with polyaniline and poly (styrene sulfonate) were used by electrical impedance measurements on analytes related to fish meat degradation (ammonia, methylamine, and trimethylamine) [79]. (b)
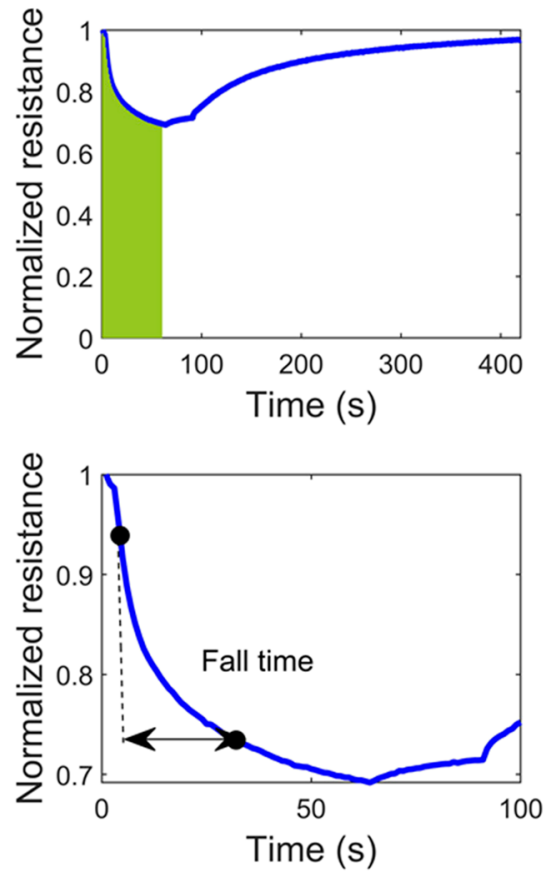

(d)

Figure 12: Four features extracted from the normalized signal of nanowire $\mathrm{SnO}_{2}$ sensor: (a) variation of resistance from the baseline (DR/ $\left.R_{0}\right)$; (b) area under the signal up to the minimum (in green); (c) total area under the signal (in green); and (d) fall time between 10 and $90 \%$ of the signal drop. Reprinted with permission from ref. [74]. 


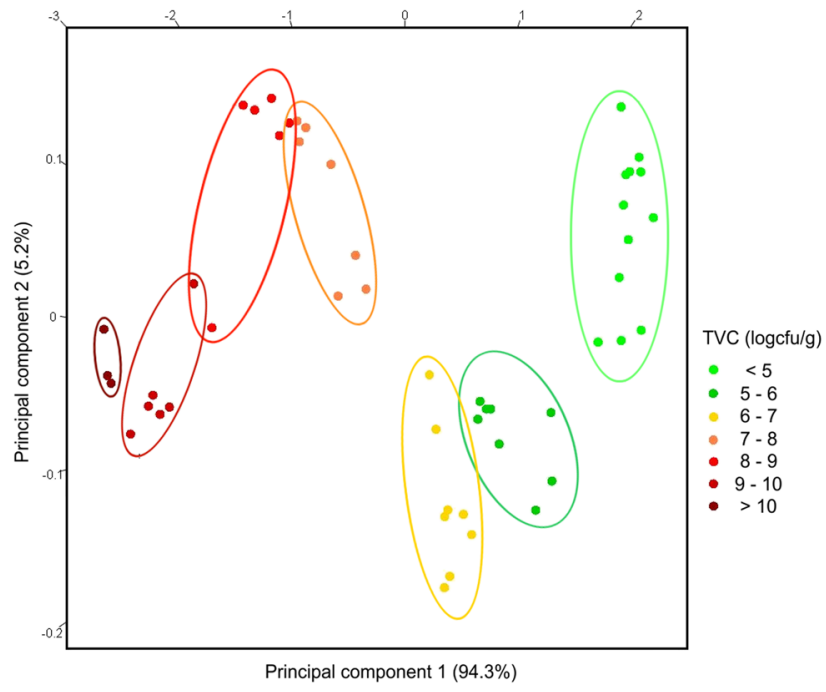

Figure 13: PCA plot of random samples of rainbow trout. The color of the points indicates the $\log ($ TVC) according to the scale on the right. Reprinted with permission from ref. [75].
The relative electrical resistance response as a function of frequency was used for multivariate data analysis. The electronic nose was tested in the range $5-15 \mathrm{ppm}$ with ammonia, methylamine, and trimethylamine. Using nonlinear interactive document mapping, the device was able to qualitatively distinguish fish samples stored at $0,24,30$, and $48 \mathrm{~h}$. Some characteristics and parameters of the electronic noses analyzed in this section are compared in Table 2.

\subsection{Health}

Carmona et al. used an electronic nose to monitor the growth of $E$. coli in water, in order to assess whether it can detect traces of the bacterium in drinking water and thus prevent water-borne diseases [80]. The $\mathrm{pH}$ and optical density measurements are very well correlated, while the plot made with the measurements of the electronic nose shows a drift of the points over time that

Table 2: List of scientific papers on electronic noses based on metal oxide nanowires applied to agrifood products

\begin{tabular}{|c|c|c|c|c|c|c|}
\hline Metal oxides & Decoration & Target gas & Temperature $\left({ }^{\circ} \mathrm{C}\right)$ & Array difference & Brain & Ref. \\
\hline $\mathrm{SnO}_{2}$ & $\mathrm{Pd}$ & $\begin{array}{l}\text { Isopropyl alcohol, ethanol, toluene, } \\
\text { CO, diluted beverages }\end{array}$ & 290 & $\begin{array}{l}\text { Width + surface } \\
\text { decoration }\end{array}$ & $\begin{array}{l}\text { Radial } \\
\text { plot, LDA }\end{array}$ & {$[58]$} \\
\hline $\mathrm{SnO}_{2}$ & - & $\mathrm{NH}_{3}, \mathrm{H}_{2} \mathrm{~S}, \mathrm{CO}$, ethanol, coffee & 450 & Materials & $\begin{array}{l}\text { Radar } \\
\text { plot, PCA }\end{array}$ & [59] \\
\hline $\mathrm{SnO}_{2}$ & - & Coffee roasting & $350-400$ & Materials & PCA & {$[60$} \\
\hline $\mathrm{SnO}_{2}$ & - & Coffee roasting & $350-400$ & Materials & PCA & [61] \\
\hline $\mathrm{SnO}_{2}$ & - & Tomato paste + vegetable soup & Not available & Materials & PCA, LDA & {$[62]$} \\
\hline $\mathrm{SnO}_{2}, \mathrm{Cr}_{2} \mathrm{TiO}_{5}, \mathrm{WO}_{3}$ & - & Different garlic cultivars & Not available & Materials & LDA & {$[63]$} \\
\hline $\mathrm{SnO}_{2}$ & - & Banana, guava, orange & Not available & Materials & PCA & {$[64]$} \\
\hline $\mathrm{ZnO}, \mathrm{SnO}_{2}$ & - & Parmigiano cheese & Not available & Materials & PCA & {$[65]$} \\
\hline $\mathrm{ZnO}, \mathrm{SnO}_{2}$ & - & Parmigiano cheese & $280-500$ & Materials & PCA & {$[66$} \\
\hline $\mathrm{ZnO}, \mathrm{SnO}_{2}$ & - & Parmigiano cheese & $350-500$ & Materials & PCA & {$[67]$} \\
\hline $\mathrm{ZnO}, \mathrm{SnO}_{2}$ & - & Grated parmigiano cheese & Not available & Materials & PCA & {$[68$} \\
\hline $\mathrm{ZnO}, \mathrm{SnO}_{2}$ & - & Parmigiano cheese & $245-500$ & Materials & PCA & {$[69]$} \\
\hline $\begin{array}{l}\mathrm{ZnO}, \mathrm{TiO}_{2} \\
\mathrm{SnO}_{2}, \mathrm{CuO}\end{array}$ & $\mathrm{Au}$ & Parmigiano and other cheeses & 400 & $\begin{array}{l}\text { Materials, signal } \\
\text { features }\end{array}$ & PLS-DA & {$[70]$} \\
\hline $\mathrm{SnO}_{2}, \mathrm{CuO}$ & $\mathrm{Au}$ & Grated parmigiano cheese & $350-400$ & Materials & $\begin{array}{l}\text { PLS- } \\
\text { DA, ANNs }\end{array}$ & [71] \\
\hline $\mathrm{SnO}_{2}, \mathrm{CuO}$ & $\mathrm{Au}$ & Campylobacter jejuni & $350-400$ & Materials & PCA & [72] \\
\hline $\mathrm{SnO}_{2}, \mathrm{CuO}, \mathrm{WO}_{3}$ & - & $\begin{array}{l}\text { Ethanol, acetone, nitrogen dioxide, } \\
\text { ozone }\end{array}$ & $200-400$ & Materials & $\begin{array}{l}\text { radial } \\
\text { plot, PCA }\end{array}$ & [73] \\
\hline $\mathrm{SnO}_{2}, \mathrm{CuO}$ & $\mathrm{Au}$ & Parmigiano cheese & $350-400$ & $\begin{array}{l}\text { Materials, signal } \\
\text { features }\end{array}$ & ANN & [74] \\
\hline $\mathrm{SnO}_{2}$ & - & Rainbow trout fish & $200-300$ & Temperature & PCA & [75] \\
\hline $\mathrm{SnO}_{2}$ & - & Pork, marble trout fish & $200-360$ & Temperature & PCA, SVM & [76] \\
\hline $\mathrm{SnO}_{2}$ & - & Healthy and infested tomato plants & Not available & Materials & PCA, HCA & [77] \\
\hline $\mathrm{SnO}_{2}$ & - & E. coli on chicken meat & Not available & Materials & SVM, RF & {$[78]$} \\
\hline $\begin{array}{l}\mathrm{SiO}_{2}: \ln _{2} \mathrm{O}_{3}, \mathrm{SiO}_{2} \\
\mathrm{SiO}_{2}: \mathrm{ZnO}\end{array}$ & PANI, PSS & $\mathrm{NH}_{3}, \mathrm{MA}, \mathrm{TMA}$, fish, degraded fish & 25 & Materials & IDMAP & {$[79]$} \\
\hline
\end{tabular}


reflects the change in the headspace due to the growth of bacteria.

The same EN, using two nanowire-based sensors, was used to detect the presence of $E$. coli and L. monocytogenes in potable water [81]. The system was capable of detecting the presence of bacteria, and the lines that the dots follow in the PCA plots indicate the potential to track bacterial growth over time in a qualitative way. The lack of a comparison with a technique that measured the concentration of bacteria does not allow us to have an estimate, even qualitative, of the limit of detection.

The microbiotic contamination detection performance of an electronic nose was tested against mold, spoilage lactic acid bacteria (LAB), and coliform bacteria [82]. The system was able to follow the growth of mold in coffee beans over time and detect the presence of different types of LAB bacteria compared to an uncontaminated sample. It was also able to detect the presence and growth over time of coliform bacteria in the water of a toilet and well.

An electronic nose consisting of six sensors based on differently decorated $\mathrm{WO}_{3}$ nanowires was compared with an electronic nose based on six commercial $\mathrm{SnO}_{2}$ sensors, testing them on the breath of smokers from that of nonsmokers [83]. The PCA plots show qualitative classification with both ENs but the confusion matrix obtained with SVM showed a success rate of 99.09 and $94.59 \%$ for $\mathrm{WO}_{3}$ and $\mathrm{SnO}_{2}$ sensor array, respectively.

An electronic nose based on six sensors, three of which of $\mathrm{ZnO}$ and $\mathrm{SnO}_{2}$ nanowires, was used to analyze the growth of skin microbiota in an artificial sweat solution [84]. Three different microbial blends (each composed of a bacterium, a yeast, and a fungus) were inoculated at concentrations of 3.75 and $1.25 \times 10^{6} \mathrm{CFU} / \mathrm{mL}$ for prokaryotes and eukaryotes, respectively. A 2D PCA plot is shown in Figure 14 demonstrates that the system was able to qualitatively distinguish mixture B (E. coli, Rhodotorula, and FGO3) and detect its development over time. The achieved results show that the electronic nose can discriminate the microorganism blends from the VOCs emitted by the microbial metabolism.

A similar device was used by the same group to detect the presence of microbiological pollution in water [85]. The electronic nose was able to qualitatively distinguish potable water from water contaminated with pathogenic microorganisms such as Escherichia coli, Salmonella typhimurium, Vibrio cholerae, and Pseudomonas aeruginosa, detecting the volatiles they emit (like indole, a volatile typically emitted by $E$. coli).

Five different metal oxides, one p-type $(\mathrm{NiO})$ and four n-type $\left(\mathrm{WO}_{3}, \mathrm{SnO}_{2}, \mathrm{ZnO}\right.$, and $\left.\mathrm{Nb}_{2} \mathrm{O}_{5}\right)$ were assembled into an electronic nose and used to discriminate between pure and contaminated water [86]. After a first phase in which the performance of each sensor was assessed in detail, the electronic nose was tested on drinking and contaminated water samples and was able to distinguish them without any training (through a PCA plot). Using a gas chromatograph, the volatiles that most distinguish the samples were found during microbiotic growth over the course of a week.

Six sensors based on MO nanowires, some of which superficially decorated, were used in an electronic nose to discriminate potable water, wastewater, and wastewater containing cyanide [87]. An ANN was trained and then used to classify the water samples, achieving a classification rate equal to $97.62 \%$. The main volatiles present in different water samples were found using gas chromatography - mass spectrometry.

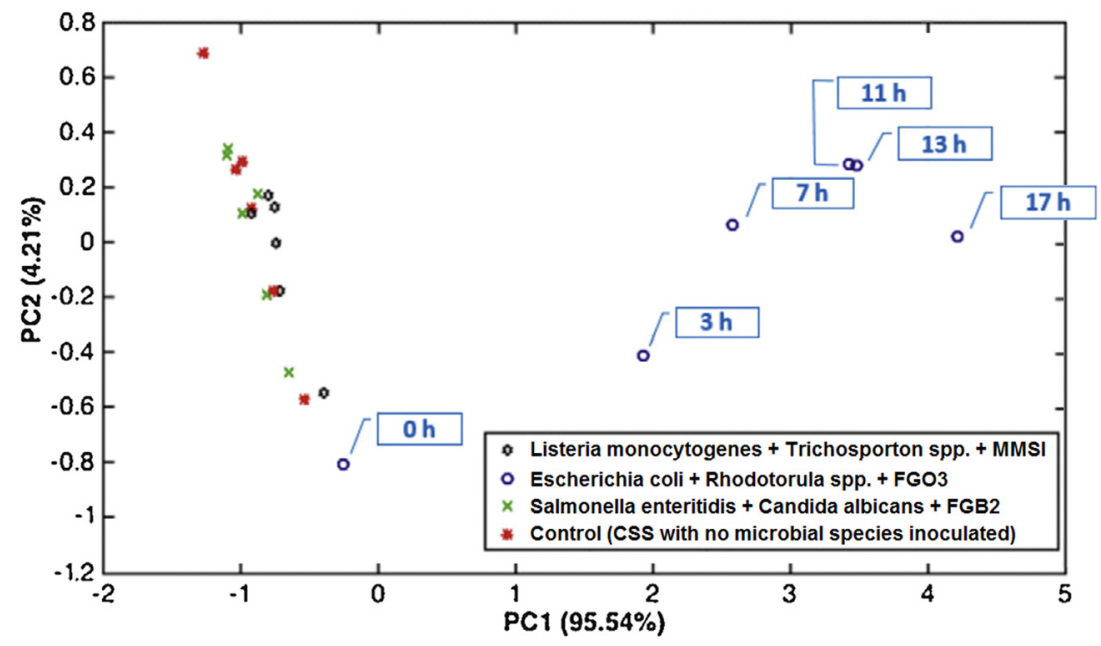

Figure 14: A PCA plot of different microbial blends along the $20 \mathrm{~h}$ analysis. Modified with permission from ref. [84]. 
Five commercial sensors (Figaro Engineering Inc., Osaka, Japan) each based on a single metal oxide were used to investigate the breath of patients with chronic obstructive pulmonary disease and lung cancer. For each of the 200 participants, fasting for $2 \mathrm{~h}$, a measurement of $120 \mathrm{~s}$ was acquired and then was analyzed using different ensemble learning methods. Using the XGBoost algorithm, the system gave an accuracy, sensitivity, and specificity of 79.3, 70.0, and 84.2\%, respectively, for lung cancer detection, and $76.7,66.7$, and $83.3 \%$ for chronic obstructive pulmonary disease detection [88]. Some characteristics and parameters of the electronic noses analyzed in this section are compared in Table 3

\subsection{Security}

In order to demonstrate the feasibility of an electronic nose based on 1D nanomaterials, Chen et al. fabricated trinitrotoluene (TNT) sensors based on single-wall carbon nanotubes (SWCNTs) and ZnO nanowires [89]. The sensors were able to detect the presence of TNT down to a few parts per billion ( 8 and $60 \mathrm{ppb}$ for SWCNTs and $\mathrm{ZnO}$ nanowires, respectively) at room temperature. The responses of the two materials are different (responses of SWCNTs are linear up to $1 \mathrm{ppm}$, while those of nanowires tends to saturate) and therefore prove to be suitable for use in an electronic nose.

An electronic nose using $\mathrm{SnO}_{2}$ nanowires and other metal oxides in a thin film form was tested with simulants of chemical warfare agents: acetonitrile as a simulant for cyanide compounds and dimethyl methylphosphonate as a simulant for the nerve agent [90]. The specific response intensities of the different materials to the tested gases resulted in a sort of "fingerprint" of the gases, demonstrating the potential as an electronic nose.

An integrated sensor array fabricated in the "print and fry" technique and consisting of 16 segments with different densities of $\mathrm{SnO}_{2}$ nanowires (like the KAMINA approach) was tested to detect explosive materials and the smell of burning from several common materials [91]. During various tests, the sensor was shown to distinguish the smell of burning polypropane, polyethane, beech, polychlorinated biphenyl, cotton, and paper, using LDA, with a separation quality of $74.5 \%$. Furthermore, the electronic nose distinguished ammonium nitrate, nitro benzene, nitrotoluene, and dinitrotoluene with a separation quality of $53.3 \%$ working at $25^{\circ} \mathrm{C}$ (activated under UV illumination) and $70 \% \mathrm{RH}$.

An electronic nose based on a $4 \times 3$ array of sensors based on different metal oxides $\left(\mathrm{SnO}_{2}, \mathrm{WO}_{3}, \mathrm{ZnO}\right.$, and $\mathrm{TiO}_{2}$ ) with different surface decorations ( $\mathrm{Al}, \mathrm{Ti}$, and $\mathrm{Au}$ ) was used to detect toxic gases $\left(\mathrm{NO}_{2}, \mathrm{NO}, \mathrm{H}_{2} \mathrm{~S}\right)$ [92]. Using a bar plot of the responses of the 12 sensors as a fingerprint of each gas, the authors demonstrated the feasibility of an electronic nose capable of qualitatively distinguishing the three target gases.

An array of 16 resistive sensors based on random densities of $\mathrm{SnO}_{2}$ nanowires was used to distinguish the preburning smell of different substances [93]. The electronic nose was working at room temperature in $50 \% \mathrm{RH}$, illuminated by ultraviolet light. After a first phase of measuring single gases (isopropanol, CO, benzene), the electronic nose was tested with different substances heated up to $200^{\circ} \mathrm{C}$. At this temperature, the system was able to distinguish cotton, beech, and polychlorinated biphenyl. The dynamic resistance of the sensors was used as input

Table 3: List of scientific papers on electronic noses based on metal oxide nanowires applied to the health field

\begin{tabular}{|c|c|c|c|c|c|c|}
\hline $\begin{array}{l}\text { Metal } \\
\text { oxides }\end{array}$ & Decoration & Target gas & Temperature $\left({ }^{\circ} \mathrm{C}\right)$ & $\begin{array}{l}\text { Array } \\
\text { difference }\end{array}$ & Brain & Ref. \\
\hline $\mathrm{SnO}_{2}$ & - & VOCs from $E$. coli & Not available & Materials & PCA & {$[80]$} \\
\hline $\mathrm{ZnO}, \mathrm{SnO}_{2}$ & - & VOCs from bacteria & Not available & Materials & PCA & {$[81]$} \\
\hline $\mathrm{SnO}_{2}$ & - & Coffee, water & Not available & Materials & PCA & {$[82]$} \\
\hline $\mathrm{SnO}_{2}, \mathrm{WO}_{3}$ & $\begin{array}{l}\mathrm{Au}, \mathrm{Pt}, \mathrm{Pt}-\mathrm{Au} \text {, } \\
\mathrm{Ni}, \mathrm{Fe}\end{array}$ & Smokers/nonsmokers breath air & Not available & Materials & $\begin{array}{l}\text { radar plot, } \\
\text { PCA, SVM }\end{array}$ & {$[83]$} \\
\hline $\mathrm{ZnO}, \mathrm{SnO}_{2}$ & - & Skin microbiota & $280-500$ & Materials & PCA & {$[84]$} \\
\hline $\mathrm{ZnO}, \mathrm{SnO}_{2}$ & - & Indole (2,3-benzopyrrole) from $E$. coli & 400 & Materials & PCA & {$[85]$} \\
\hline $\begin{array}{l}\mathrm{NiO}, \mathrm{WO}_{3} \\
\mathrm{ZnO}, \mathrm{SnO}_{2}\end{array}$ & $\mathrm{Au}$ & Water $+E$. coli & $200-400$ & Materials & PCA & {$[86]$} \\
\hline $\mathrm{SnO}_{2}$ & $\mathrm{Au}$ & Water, wastewater + cyanide & Not available & Materials & PCA, ANN & {$[87]$} \\
\hline $\mathrm{SnO}_{2}$ & - & $\begin{array}{l}\text { Breath from healthy people and patients } \\
\text { diagnosed with chronic obstructive } \\
\text { pulmonary disease and lung cancer }\end{array}$ & Not available & Materials & $\begin{array}{l}\text { XGBoost, } \\
\text { AdaBoost, RF }\end{array}$ & {$[88]$} \\
\hline
\end{tabular}


features for LDA. The electronic nose successfully discriminated all the substances at preburning temperature with a separation quality of $88 \%$. A real field scenario was set up, with the electronic nose inside a real room, far from the heated materials. Also, in this case, the system was able to distinguish the materials heated, with a separation quality of $86 \%$. In this way, an alarm can be set to also indicate the type of material that could trigger the fire.

An array of six commercial $\mathrm{SnO}_{2}$-based gas sensors were used to study wood samples from two types of plants: sugi (Cryptomeria japonica) and karamatsu (Larix kaempferi) and detect the presence of fungi ( $F$. palustris and T. versicolor). The electronic nose was able to discriminate in a qualitative way (PCA) the wooden samples infested by fungi [94].

Nanostructures of $\mathrm{Mn}_{3} \mathrm{O}_{4}$ were grown by vapor deposition in different atmospheres $\left(\mathrm{O}_{2}\right.$ and $\left.\mathrm{O}_{2}+\mathrm{H}_{2} \mathrm{O}\right)$ in order to study how the growth conditions varied their characteristics and sensing performance [95]. The sensors were tested toward acetonitrile $\left(\mathrm{CH}_{3} \mathrm{CN}\right)$ and dimethyl methyl phosphonate (DMMP), both used as simulants for cyanide warfare agents. Increasing the working temperature from 200 to $300^{\circ} \mathrm{C}$, the sensors were able to detect $\mathrm{CH}_{3} \mathrm{CN}$ with good selectivity.

Nanostructured composite materials based on $\mathrm{Mn}_{3} \mathrm{O}_{4}$ have been used as conductometric sensors to detect low concentrations of chemical warfare agents [96]. Pristine $\mathrm{Mn}_{3} \mathrm{O}_{4}, \mathrm{Ag} / \mathrm{Mn}_{3} \mathrm{O}_{4}$, and $\mathrm{Au} / \mathrm{Mn}_{3} \mathrm{O}_{4}$ were tested for di(propylene glycol) monomethyl ether (DPGME), acetonitrile $\left(\mathrm{CH}_{3} \mathrm{CN}\right)$, and DMMP, as well as acetone and ethanol. The sensors proved to be selective toward chemical warfare agent simulants, especially working at $300^{\circ} \mathrm{C}$. In particular, $\mathrm{Au} / \mathrm{Mn}_{3} \mathrm{O}_{4}$ showed high selectivity for DPGME

Composite nanostructures of $\mathrm{Fe}_{2} \mathrm{O}_{3} / \mathrm{Mn}_{3} \mathrm{O}_{4}$ and $\mathrm{ZnO} /$ $\mathrm{Mn}_{3} \mathrm{O}_{4}$ have been used as selective sensors towards ammonia with respect to nitrogen dioxide and acetonitrile $\left(\mathrm{CH}_{3} \mathrm{CN}\right)$, a toxic gas used as a simulant of cyanide warfare agents [97]. Composite nanomaterials are selective toward ammonia and $\mathrm{NO}_{2}$, while pristine $\mathrm{Mn}_{3} \mathrm{O}_{4}$ shows a marked selectivity toward $\mathrm{CH}_{3} \mathrm{CN}$ between 200 and $300^{\circ} \mathrm{C}$.

Composite sensors based on almost one-dimensional $\mathrm{CuO} / \mathrm{MnO}_{2}$ and $\mathrm{SnO}_{2} / \mathrm{MnO}_{2}$ nanostructures were used to detect di(propyleneglycol) monomethyl ether and DMMP (used as simulants for chemical warfare agents) and hydrogen. Working at $250^{\circ} \mathrm{C}$, the metal oxide heteronanostructures showed a remarkable selectivity toward the gas chemical warfare agents [98]. The use at three different temperatures $\left(150-250^{\circ} \mathrm{C}\right)$ could increase the selectivity even more. Some characteristics and parameters of the electronic noses analyzed in this section are compared in Table 4.

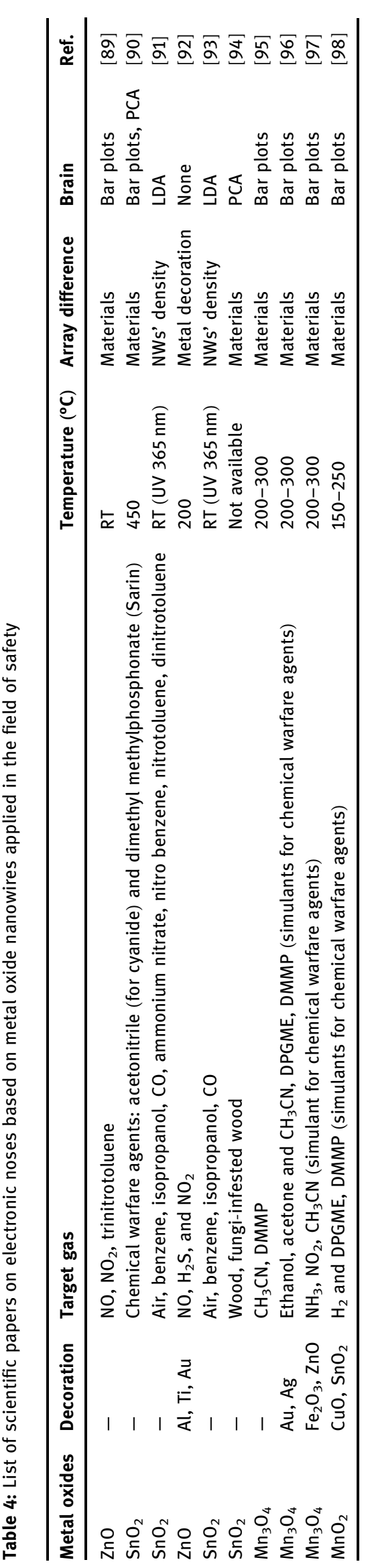




\section{Discussion}

Some conclusions can be drawn from the collection of articles discussed. First, despite the large number of scientific articles on gas sensors, nanowires, and electronic noses, in the last decade, there have been a few articles on electronic noses using metal oxide nanowires. It is reasonable to think that this is due to the different technological maturity of the two topics: electronic noses have been studied since the 1980s, while only in the last 15 years has it been possible to integrate nanowires into functional devices.

Metal oxide nanowires are a widely used material for gas sensors. Initially, the focus was on n-type semiconductors, which perform better, but recently p-type semiconductors are also gaining momentum as they are useful for increasing selectivity.

As seen in the left part of Figure 15, this different interest in metal oxides is confirmed by the articles studied here: $\mathrm{SnO}_{2}$ is by far the most used, followed by $\mathrm{ZnO}$. The other oxides are used in about one-third of cases.

Recently, the performance of gas sensors based on MO nanowires has been greatly improved by decorating their surface with nanoparticles. At first, the decoration was carried out with precious metals $(\mathrm{Ag}, \mathrm{Au}, \mathrm{Pt})$, then it was extended to metal oxides and finally to a wide range of materials. This technological evolution is visible in the right part of Figure 13, in which most of the articles discussed here are not superficially decorated, and the most used nanoparticles are those of $\mathrm{Au}$ and Pt. The decoration with metal oxides is receiving great attention also for the possibility of creating $\mathrm{p}-\mathrm{n}$ junctions and it is growing strongly in recent times.

Using different metal oxides or surface decoration with different materials is the most common way to make a sensor array that is the basis for an electronic nose. Since an electronic nose tries to mimic the olfactory system of mammals, made up of many receptors with different properties, the first devices were born using sensors made of different materials. Even when nanowires began to be used, this approach remained the most common, whether different sensors were used or integrated on a single platform. As can be seen in the left part of Figure 16, the material and the surface decoration (another aspect of the material) are the basis of almost three-quarters of the devices analyzed.

However, as can be seen in the figure, the use of nanowires has broadened the range of parameters that can be used to differentiate the sensors in the array and generate selectivity. Different materials and different signal parameters were already used for macroscopic sensors, but using nanowires it is also possible to vary their density and make them work in a temperature gradient, for example.

Another aspect to consider, which has been used as a framework for this review, is the application for which the electronic noses were used. Section 3 has been divided into subsections relating to the pure scientific-technological aspect and use in the agrifood, health, and safety fields. The proportions of these uses are shown in the right part of Figure 16. It can be clearly seen that in the vast majority of cases the electronic noses are used in the laboratory and tested with pure gases, for purely scientific tests. The lack of real applications may indicate that technological maturity has not yet been reached.

This fact is confirmed by the graphs in Figure 17. The left side shows the method used to illustrate the final results obtained by the electronic nose.

In some cases, these are real machine learning algorithms, often a simple visualization of the points, and sometimes a simple graph of the raw responses. As can
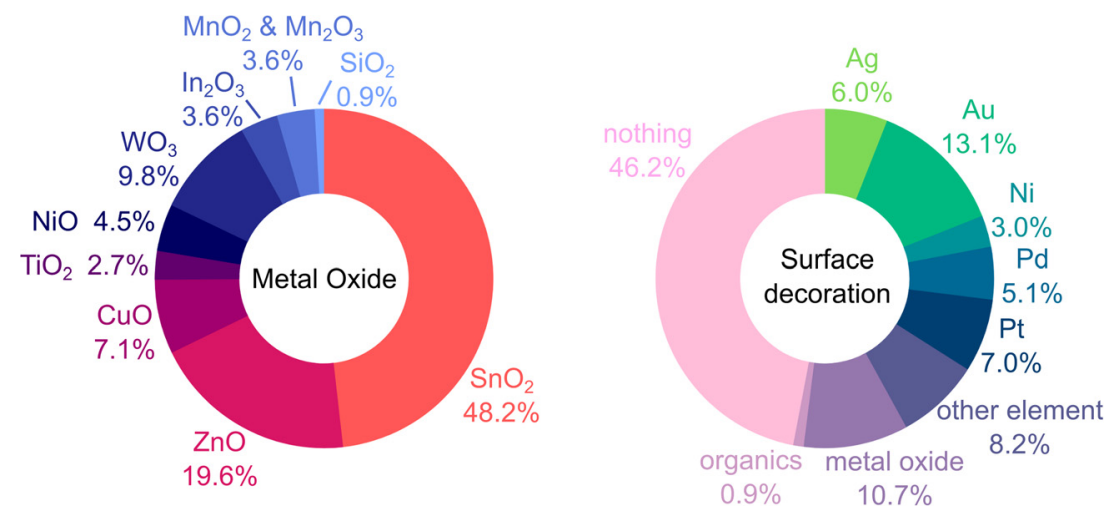

Figure 15: Frequency of use of different metal oxides in the fabrication of electronic noses based on nanowires (left); frequency of use of different materials as superficial decoration for MO nanowires (right). 


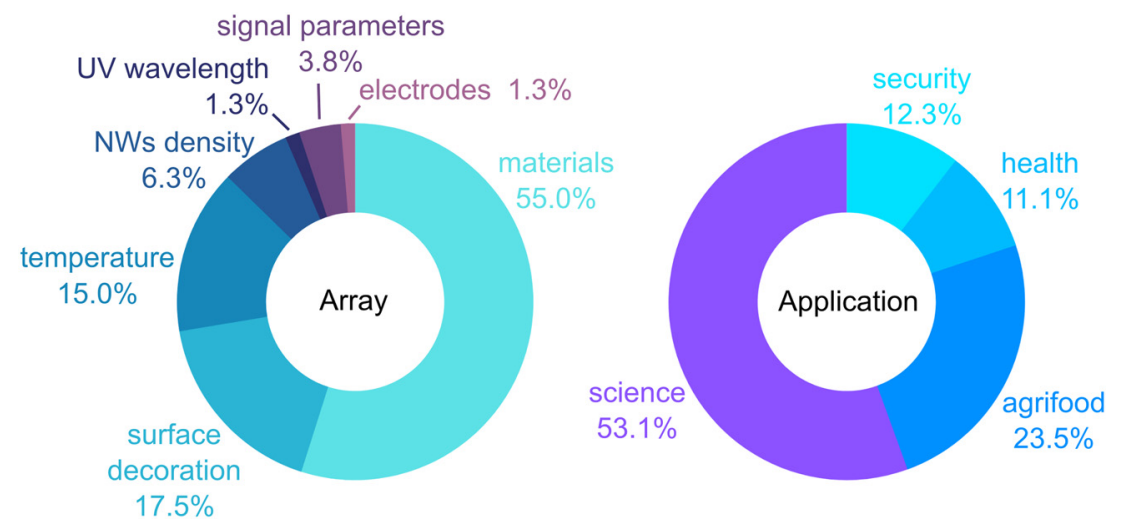

Figure 16: Features that differentiate the sensors in the array that makes up the electronic nose (left); application for which the electronic nose was tested (right).

be seen, PCA is used in almost half of the cases, which is a method of reducing dimensionality in order to visualize the data, and in this case, the electronic nose does not autonomously give any response. The maximum achievable result is the comparison of new measurements with those used for training (qualitative classification), but it is done by the operator with human eyes and brain, and not by the electronic nose. The real algorithms that give an output (classification or even quantification) are LDA, PLS-DA, SVM, and ANN, and together they add up to about one-third of the cases studied. In $20 \%$ of cases, the authors simply indicated the response of the various sensors that make up the electronic nose giving the values or graphing them in box plots, bar plots, or radar plots. The case of RGB encoding is similar to a litmus test, which gives an approximate quantification but needs a human operator (like PCA).

The right part of Figure 17 shows the type of final information that the electronic nose provides. In $20 \%$ of cases, there is only a proof of concept, which usually consists of the raw responses from the sensors (a sort of fingerprints). In most cases, the device only gives a qualitative classification, i.e., a visual comparison (which needs a human operator, as the system is not capable of it) between the calibration data and any new measurement. Only $9.1 \%$ of the ENs provide a real classification obtained autonomously. Although it is the final goal of an electronic nose, only a small part of the systems analyzed is able to give a quantitative estimate autonomously. Depending on the application, this can be an important defect: in certain contexts, it is sufficient to distinguish different cases (for example, patients with a certain pathology from healthy individuals), but in others it is necessary to understand which gas is present and in what concentration (for example, a fire sensor that must not misinterpret cooking smells).

\section{Conclusions and outlook}

The scenario depicted by the articles analyzed in this review indicates a recent and not yet fully developed combination of MO nanowires and machine learning
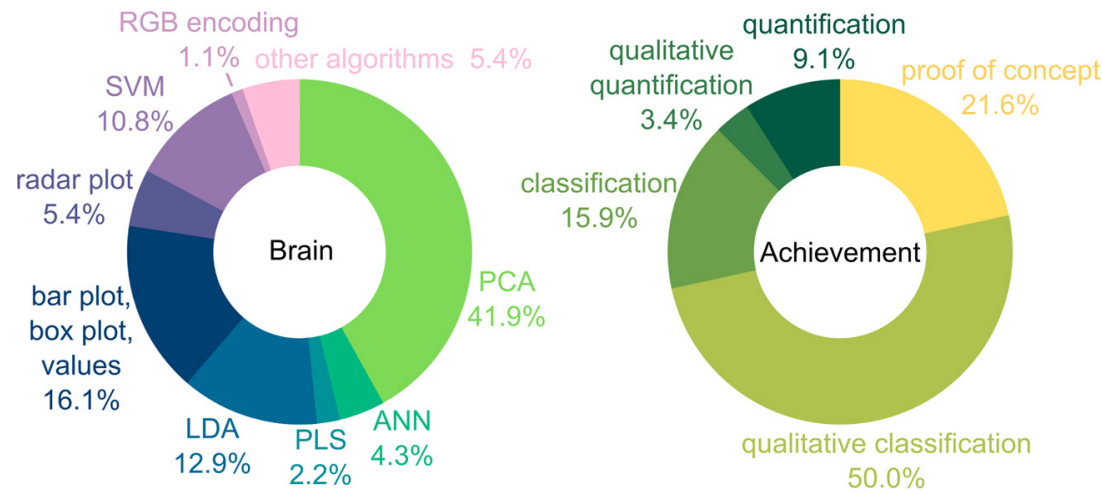

Figure 17: Features that differentiate the sensors in the array that makes up the electronic nose (left); application for which the electronic nose was tested (right). 
algorithms for fabricating electronic noses. There is certainly a lot of potential in this synergy (as demonstrated by the flourishing of innovative approaches), but the results are still limited in most cases. This is likely due to the inherently interdisciplinary nature of this subject, which combines materials science and nanotechnology (growth of nanowires), micromachining (electrodes and device), electronics (signal acquisition and processing), and machine learning (statistical analysis of responses).

The scientific literature shows a much greater development in the aspects related to materials science and nanotechnologies, while the implementation of data mining and artificial intelligence methods is still limited, both for the extraction of features and their analysis. This is probably because the authors are largely experts in resistive gas sensors based on nanostructured metal oxides, who have independently acquired basic knowledge about machine learning, while the opposite situation is not common. This imbalance is demonstrated by the attention given to the growth and characterization of nanomaterials or to the improvement of individual sensors (response intensity, response and recovery time, limit of detection), while little attention is given to features extraction and their processing (in many cases, these passages are not even present), which are equally important for the final performance of an electronic nose.

Another weakness of nanowire-based electronic noses is that they are almost always tested under laboratory conditions, with exact concentrations from pure gas cylinders. The few applications with real samples are also carried out under simplified laboratory conditions, without all the possible adversities of field measurements (including the wide variability of real samples). This type of experiment works for single selective sensors to be applied under specific conditions (no or few interfering gases, narrow temperature, and humidity range) but not for electronic noses. This type of device has been designed precisely to identify gases and volatile organic compounds in the presence of many interfering molecules, and therefore, field measurements under realistic conditions are needed. The absence of real-world applications in the reviewed literature indicates that research on electronic noses based on metal oxide nanowires is still in its infancy: better fundamental research and wider real-world applications are still needed.

It should be emphasized that several new approaches have recently been developed, both regarding the differentiation of sensors in the array and the choice of features to extract and process. In this sense, the new approaches shown in this excursus, even very different from each other, demonstrate the interest of the scientific community in the topic. Traditional electronic noses, composed of single macroscopic gas sensors, continue to provide interesting results, but the new integrated architectures based on nanowires offer very important advantages in the era internet of things. Given the very wide diffusion and rapid innovation of personal technological tools (smartphones, smartwatches) and the need for sensors to collect information about the world around us, this new generation of electronic noses will surely attract more and more interest also through the synergy of nanoscience and artificial intelligence.

Acknowledgments: The authors would like to thank Kristyna Alessandrini for her invaluable help in correcting the syntax of the manuscript.

Funding information: This work was financially supported by the Vingroup Innovation Foundation (VINIF) annual research support program with project code VINIF.2019.DA10. F. Gasperi and F. Biasioli acknowledge the support of the Autonomous Province of Trento (Program Agreement ADP 2020).

Author contributions: All authors have accepted responsibility for the entire content of this manuscript and approved its submission.

Conflict of interest: The authors state no conflict of interest.

\section{References}

[1] Research carried out on the Scopus search engine; October 7, 2021.

[2] Seyama T, Kato A, Fujishi K, Nagatani M. A new detector for gaseous components using semiconductive thin films. Anal Chem. 1962;34:1502-3.

[3] Kim J-H, Mirzaei A, Osada M, Kim HW, Kim SS. Hydrogen sensing characteristics of Pd-decorated ultrathin $\mathrm{ZnO}$ nanosheets. Sensors Actuators, B Chem. 2021;329:129222. doi: 10.1016/j.snb.2020.129222.

[4] Navale S, Shahbaz M, Mirzaei A, Kim SS, Kim HW. Effect of Ag addition on the gas-sensing properties of nanostructured resistive-based gas sensors: an overview. Sensors. 2021;21:6454. doi: 10.3390/s21196454.

[5] Tshabalala ZP, Mokoena TP, Jozela M, Tshilongo J, Hillie TK, Swart $\mathrm{HC}$, et al. $\mathrm{TiO}_{2}$ nanowires for humidity-stable gas sensors for toluene and xylene. ACS Appl Nano Mater. 2021;4:702-16. doi: 10.1021/acsanm.0c02963.

[6] Kim T-H, Jeong S-Y, Moon YK, Lee J-H. Dual-mode gas sensor for ultrasensitive and highly selective detection of xylene and toluene using $\mathrm{Nb}$-doped $\mathrm{NiO}$ hollow spheres. Sens Actuators, B. 2019;301:127140. doi: 10.1016/j.snb.2019.127140.

[7] Motsoeneng RG, Kortidis I, Ray SS, Motaung DE. Designing $\mathrm{SnO}_{2}$ nanostructure-based sensors with tailored selectivity 
towards propanol and ethanol vapors. ACS Omega. 2019;4:13696-709. doi: 10.1021/acsomega.9b01079.

[8] Neri G. Thin 2D: the new dimensionality in gas sensing. Chemosensors. 2017;5:21. doi: 10.3390/ chemosensors5030021.

[9] Tonezzer M, Hieu NV. Size-dependent response of singlenanowire gas sensors. Sens Actuators, B. 2012;163:146-52. doi: 10.1016/j.snb.2012.01.022.

[10] Liu J, Lv J, Xiong H, Wang Y, Jin G, Zhai Z, et al. Size effect and comprehensive mathematical model for gas-sensing mechanism of $\mathrm{SnO}_{2}$ thin film gas sensors. J Alloys Compd. 2022;898:162875. doi: 10.1016/j.jallcom.2021.162875.

[11] Tonezzer M, Dang TTL, Bazzanella N, Nguyen VH, lannotta S. Comparative gas-sensing performance of $1 \mathrm{D}$ and $2 \mathrm{D} \mathrm{ZnO}$ nanostructures. Sensors Actuators, B Chem. 2015;220:1152-60. doi: 10.1016/j.snb.2015.06.103.

[12] Wold S, Sjöström M, Eriksson L. PLS-regression: a basic tool of chemometrics. Chemometrics and Intelligent Laboratory Systems. 2001;58:109-30. doi: 10.1016/S0169-7439(01) 00155-1.

[13] Esposito Vinzi V, Chin WW, Henseler J, Wang H, editors. Handbook of Partial Least Squares. Springer Handbooks of Computational Statistics. Berlin, Heidelberg: Springer; ISBN 978-3-540-32827-8.

[14] McCulloch WS, Pitts W. A logical calculus of the ideas immanent in nervous activity. Bull Math Biol. 1943;5:115-33. doi: 10.1007/BF02459570.

[15] Gardner JW, Bartlett PN. A brief history of electronic noses. Sensors Actuators, B Chem. 1994;18-19:211-20. doi: 10.1016/ 0925-4005.

[16] Haugen J-E, Kvaal K. Electronic nose and artificial neural network. Meat Science. 1998;49:S273-86. doi: 10.1016/09254005(94)87085-3.

[17] Sysoev VV, Button BK, Wepsiec K, Dmitriev S, Kolmakov A. Toward the nanoscopic "electronic nose": hydrogen vs carbon monoxide discrimination with an array of individual metal oxide nano- and mesowire sensors. Nano Lett. 2006;6:1584-8. doi: 10.1021/nl060185t.

[18] Sysoev VV, Goshnick J, Schneider T, Strelcov E, Kolmakov A. A gradient microarray electronic nose based on percolating $\mathrm{SnO}_{2}$ nanowire sensing elements. Nano Lett. 2007;7:3182-8. doi: $10.1021 / \mathrm{nl} 071815$.

[19] Miller A, Carchman R, Long R, Denslow SA. The gas-sensing characteristics of percolating $2 \mathrm{D} \mathrm{SnO}_{2}$ nanowire mats as a platform for electronic nose devices. AIP Conf Proc. 2009;1137:403-4. doi: 10.1063/1.3156563.

[20] Chen P-C, Ishikawa FN, Chang H-K, Ryu K, Zhou C. A nanoelectronic nose: a hybrid nanowire/carbon nanotube sensor array with integrated micromachined hotplates for sensitive gas discrimination. Nanotechnology. 2009;20:125503. doi: 10.1088/0957-4484/20/12/125503.

[21] Baik JM, Zielke M, Kim MH, Turner KL, Wodtke AM, Moskovits M. Tin-oxide-nanowire-based electronic nose using heterogeneous catalysis as a functionalization strategy. ACS Nano. 2010;4:3117-22. doi: 10.1021/nn100394a.

[22] Chen J, Su H, Zhou W. Gas discrimination by ZnO nanowire arrays with different metal oxide coatings. Proc IEEE Conf Nanotechnol. 2011;34-7. doi: 10.1109/ NANO.2011.6144459.
[23] Chen J, Wang K, Zhou W. Vertically aligned $\mathrm{ZnO}$ nanorod arrays coated with $\mathrm{SnO}_{2}$ /noble metal nanoparticles for highly sensitive and selective gas detection. IEEE Trans Nanotechnol. 2011;10:968-74. doi: 10.1109/TNANO.2010.2091423.

[24] Mwakikunga BW, Malwela T, Hillie KT, Ndlovu G. Towards an electronic nose based on nano-structured transition metal oxides activated by a tuneable UV light source. Proc IEEE Sens. 2011;6127403:1109-12. doi: 10.1109/ICSENS.2011.6127403.

[25] MacNaughton S, Sonkusale S, Surwade S, Ammu S, Manohar S. Electronic nose based on graphene, nanotube and nanowire chemiresistor arrays on silicon. Proc IEEE Sens. 2011;13:125-8. doi: 10.1109/ICSENS.2011.6127182.

[26] Sysoev VV, Strelcov E, Kar S, Kolmakov A. The electrical characterization of a multi-electrode odor detection sensor array based on the single $\mathrm{SnO}_{2}$ nanowire. Thin Solid Films. 2011;520:898-903. doi: 10.1016/j.tsf.2011.04.179.

[27] Su H, Chen J, Wang K, Ayyad AA, Zhou W. The electronic nose: the effect of metal oxide modifications to well-aligned $\mathrm{ZnO}$ nanowire arrays for highly sensitive and selective gas detection. Free Radical Biol Med. 2012;52:126-9. doi: 10.5162/ imcs2012/1.4.5.

[28] Sberveglieri G, Concinca I, Comini E, Falasconi M, Ferroni M, Sberveglieri V. Synthesis and integration of tin oxide nanowires into an electronic nose. Vacuum. 2012;86:532-5. doi: 10.1016/j.vacuum.2011.10.004.

[29] Zou X, Wang J, Liu X, Wang C, Jiang Y, Wang Y, et al. Rational design of sub-parts per million specific gas sensors array based on metal nanoparticles decorated nanowire enhancement-mode transistors. Nano Lett. 2013;13:3287-92. doi: 10.1021/nl401498t.

[30] Ko W, Jung N, Lee M, Yun M, Jeon S. Electronic nose based on multipatterns of $\mathrm{ZnO}$ nanorods on a quartz resonator with remote electrodes. ACS Nano. 2013;7:6685-90. doi: 10.1021/nn4027245.

[31] Hwang S, Kwon H, Chhajed S, Byon JW, Baik JM, Im J, et al. A near single crystalline $\mathrm{TiO}_{2}$ nanohelix array: enhanced gas sensing performance and its application as a monolithically integrated electronic nose. Analyst. 2013;138:443-50. doi: 10.1039/C2AN35932D.

[32] Hu Y, Lee H, Kim S, Yun M. A highly selective chemical sensor array based on nanowire/nanostructure for gas identification. Sensors Actuators, B Chem. 2013;181:424-31. doi: 10.1016/ j.snb.2013.01.084.

[33] Park WJ, Choi KJ, Kim MH, Koo BH, Lee JL, Baik JM. Selfassembled and highly selective sensors based on air-bridgestructured nanowire junction arrays. ACS Appl Mater Interfaces. 2013;5:6802-7. doi: 10.1021/am401635e.

[34] DeMeo D, MacNaughton S, Wang Z, Zhang X, Sonkusale S, Vandervelde TE. Heterogeneous metal-oxide nanowire microsensor array for gas sensing. Mater Res Express. 2014;1:1. doi: 10.1088/2053-1591/1/2/025002.

[35] Wongchoosuk C, Subannajui K, Wang C, Yang Y, Güder F, Kerdcharoen $\mathrm{T}$, et al. Electronic nose for toxic gas detection based on photostimulated core-shell nanowires. RSC Adv. 2014;4:35084-8. doi: 10.1039/c4ra06143h.

[36] Liang C, Li Y, Luo J. Room temperature gas sensing with potassium titanate nanowires. 2015 IEEE. SENSORS - Proc. 2015;13:1-4. doi: 10.1109/ICSENS.2015.7370586.

[37] Song E, Choi J-W. Multi-analyte detection of chemical species using a conducting polymer nanowire-based sensor array 
platform. Sens Actuators B Chem. 2015;215:99-106. doi: 10.1016/j.snb.2015.03.039.

[38] Tonezzer M, Le DTT, Huy TQ, lannotta S. Dual-selective hydrogen and ethanol sensor for steam reforming systems. Sens Actuators, B. 2016;236:1011-9. doi: 10.1016/ j.snb.2016.04.150.

[39] Moon HG, Jung Y, Han SD, Shim Y-S, Shin B, Lee T, et al. Chemiresistive electronic nose toward detection of biomarkers in exhaled breath. ACS Appl Mater Interfaces. 2016;8:20969-76. doi: 10.1021/acsami.6b03256.

[40] Cai B, Song Z, Tong Y, Tang Q, Shaymurat T, Liu Y. A single nanobelt transistor for gas identification: Using a gasdielectric strategy. Sensors. 2016;16:1-11. doi: 10.3390/ s16060917.

[41] Tan HM, Manh Hung C, Ngoc TM, Nguyen H, Duc Hoa N, Van Duy N, et al. Novel self-heated gas sensors using on-chip networked nanowires with ultralow power consumption. ACS Appl Mater Interfaces. 2017;9:6153-62. doi: 10.1021/ acsami.6b14516.

[42] Moon HG, Jung Y, Han SD, Shim YS, Jung WS, Lee T, et al. All villi-like metal oxide nanostructures-based chemiresistive electronic nose for an exhaled breath analyzer. Sensors Actuators, B Chem. 2018;257:295-302. doi: 10.1016/ j.snb.2017.10.153

[43] Liang C, Li Y, Luo J. Different nanowire materials localized growth and in-situ integration for electronic nose applications. Proc 2018 12th Spanish Conf Electron Devices, CDE 2018. 2018;6:8-11. doi: 10.1109/CDE.2018.8597020.

[44] Tonezzer M, Le DTT, Iannotta S, Hieu NV. Selective discrimination of hazardous gases using one single metal oxide resistive sensor. Sens Actuators B Chem. 2018;277:121-8. doi: 10.1016/j.snb.2018.08.103.

[45] Chen J, Chen Z, Boussaid F, Zhang D, Pan X, Zhao H, et al. Ultra-low-power smart electronic nose system based on threedimensional tin oxide nanotube arrays. ACS Nano. 2018;12:6079-88. doi: 10.1021/acsnano.8b02371.

[46] Hrachowina L, Domènech-Gil G, Pardo A, Seifner MS, Gràcia I, Cané $C$, et al. Site-specific growth and in situ integration of different nanowire material networks on a single chip: toward a nanowire-based electronic nose for gas detection. ACS Sensors. 2018;3:727-34. doi: 10.1021/ acssensors.8b00073.

[47] Tonezzer M, Dang LTT, Tran HQ, lannotta S. Multiselective visual gas sensor using nickel oxide nanowires as chemiresistor. Sensors Actuators, B Chem. 2018;255:2785-93. doi: 10.1016/j.snb.2017.09.094.

[48] Tonezzer M. Selective gas sensor based on one single $\mathrm{SnO}_{2}$ nanowire. Sens Actuators B Chem. 2019;288:53-9. doi: 10.1016/j.snb.2019.02.096.

[49] Bobkov A, Varezhnikov A, Plugin I, Fedorov FS, Trouillet V, Geckle U, et al. The multisensor array based on grown-on-chip zinc oxide nanorod network for selective discrimination of alcohol vapors at sub-ppm range. Sensors. 2019;19:4265. doi: $10.3390 / \mathrm{s} 19194265$.

[50] Tonezzer M, Kim J-H, Lee J-H, lannotta S, Kim SS. Predictive gas sensor based on thermal fingerprints from Pt- $\mathrm{SnO}_{2}$ nanowires. Sens Actuators B Chem. 2019;281:670-8. doi: 10.1016/j.snb.2018.10.102.
[51] Tonezzer M, Izidoro SC, Moraes JPA, Dang LTT. Improved gas selectivity based on carbon modified $\mathrm{SnO} 2$ nanowires. Front Mater. 2019;6:277. doi: 10.3389/fmats.2019.00277.

[52] Ngoc TM, Van Duy N, Hung CM, Hoa ND, Nguyen H, Tonezzer M, et al. Self-heated Ag-decorated $\mathrm{SnO}_{2}$ nanowires with low power consumption used as a predictive virtual multisensor for $\mathrm{H}_{2} \mathrm{~S}$-selective sensing. Anal Chim Acta. 2019;1069:108-16. doi: 10.1016/j.aca.2019.04.020.

[53] Thai NX, Van Duy N, Hung CM, Nguyen H, Tonezzer M, Van Hieu N, et al. Prototype edge-grown nanowire sensor array for the real-time monitoring and classification of multiple gases. J Sci Adv Mater Devices. 2020;5:409-16. doi: 10.1016/ j.jsamd.2020.05.005.

[54] Thai NX, Tonezzer M, Masera L, Nguyen H, Duy NV, Hoa ND. Multi gas sensors using one nanomaterial, temperature gradient, and machine learning algorithms for discrimination of gases and their concentration. Anal Chim Acta. 2020;1124:85-93. doi: 10.1016/j.aca.2020.05.015.

[55] Sinju KR, Ramgir NS, Pathak A, Debnath AK, Muthe KP. Multiple sensor array based on $\mathrm{ZnO}$ nanowires for electronic nose applications towards toxic gases. AIP Conf Proc. 2020;2:2265-42. doi: 10.1063/5.0017841.

[56] Tonezzer M, Armellini C, Toniutti L. Sensing performance of thermal electronic noses: a comparison between $\mathrm{ZnO}$ and $\mathrm{SnO}_{2}$ nanowires. Nanomaterials. 2021;11:2773. doi: 10.3390/ nano11112773.

[57] Kanaparthi S, Singh SG. Discrimination of gases with a single chemiresistive multi-gas sensor using temperature sweeping and machine learning. Sensors Actuators, B Chem. 2021;348:130725. doi: 10.1016/j.snb.2021.130725.

[58] Sysoev VV, Strelcov E, Sommer M, Bruns M, Kiselev I, Habicht W, et al. Single-nanobelt electronic nose: Engineering and tests of the simplest analytical element. ACS Nano. 2010;4:4487-94. doi: 10.1021/nn100435h.

[59] Ponzoni A, Zappa D, Comini E, Sberveglieri V, Faglia G, Sberveglieri G. Metal oxide nanowire gas sensors: Application of conductometric and surface ionization architectures. Chem Eng Trans. 2012;30:31-6. doi: 10.3303/CET1230006.

[60] Sberveglieri V, Pulvirenti A, Comini E, Carmona EN. What happens at the aroma of coffee beans after roasting? MOX nanowire technology by novel electronic nose to discover the finger print. Int J Smart Sens Intell Syst. 2014;7:1-4. doi: 10.21307/IJSSIS-2019-052.

[61] Sberveglieri V, Núñez E, Zappa D, Comini E, Pulvirenti A. Classification of different roasting processes by MOX nanowire. Procedia Eng. 2014;87:572-5. doi: 10.1016/ j.proeng.2014.11.553.

[62] Sberveglieri G, Zambotti G, Falasconi M, Gobbi E, Sberveglieri V. MOX-NW electronic nose for detection of food microbial contamination. Proc IEEE Sens. 2014;2014:1376-9. doi: 10.1109/ICSENS.2014.6985268.

[63] Messina V, Sance M, Grigioni G, de Reca NW. Optimization of metal oxide gas sensor in electronic nose to monitor odor profiles of garlic scape. IEEE Sens J. 2014;14:1765. doi: 10.1109/JSEN.2014.2303147.

[64] Kanade A, Shaligram AD. Development of an e-nose using metal oxide semiconductor sensors for the classification of climacteric fruits. IJSER. 2014;5:467-72. 
[65] Sberveglieri V, Carmona EN, Pulvirenti A. Nanowire sensor array for the rapid quality control on grated Parmigiano Reggiano. Proc AISEM Conference. 2015;2015:7066773-56. doi: 10.1109/AISEM.2015.7066773.

[66] Sberveglieri V, Bhandari MP, Carmona EN, Betto G, Sberveglieri G. A novel MOS nanowire gas sensor device (S3) and GC-MS-based approach for the characterization of grated parmigiano reggiano cheese. Biosensors. 2016;6:6. doi: $10.3390 /$ bios 6040060 .

[67] Zappa D, Sberveglieri V, Comini E, Barisani F, Sberveglieri G. Synthesis and characterization of zinc and tin oxide nanowires for the detection of Parmigiano Reggiano cheese. Proc Int Conf Sens Technol ICST. 2016;2016-March:178-82. doi: 10.1109/ ICSensT.2015.7438387.

[68] Bhandari MP, Carmona EN, Galstyan V, Sberveglieri V. Quality evaluation of Parmigiano Reggiano cheese by a novel nanowire device S3 and evaluation of the VOCs profile. Procedia Eng. 2016;168:460-4. doi: 10.1016/ j.proeng.2016.11.126.

[69] Sberveglieri V, Bhandari MP, Carmona EN, Betto G, Soprani M, Malla R, et al. Spectrocolorimetry and nanowire gas sensor device S3 for the analysis of Parmigiano Reggiano cheese ripening. Proc ISOEN. 2017;7968861. doi: 10.1109/ ISOEN.2017.7968861.

[70] Abbatangelo M, Núñez-Carmona E, Sberveglieri V. Application of a novel S3 nanowire gas sensor device in parallel with GCMS for the identification of Parmigiano Reggiano from US and European competitors. J Food Eng. 2018;236:36-43. doi: 10.1016/j.jfoodeng.2018.05.009.

[71] Abbatangelo M, Núñez-Carmona E, Sberveglieri V, Zappa D, Comini E, Sberveglieri G. Application of a novel S3 nanowire gas sensor device in parallel with GC-MS for the identification of rind percentage of grated Parmigiano Reggiano. Sensors. 2018;18:18. doi: 10.3390/s18051617.

[72] Núñez-Carmona E, Abbatangelo M, Sberveglieri V. Innovative sensor approach to follow Campylobacter jejuni development. Biosensors. 2019;9:bios9010008. doi: 10.3390/ bios 9010008 .

[73] Zappa D. Low-power detection of food preservatives by a novel nanowire-based sensor array. Foods. 2019;8:8. doi: 10.3390/ foods 8060226 .

[74] Abbatangelo M, Núñez-Carmona E, Sberveglieri V, Zappa D, Comini E, Sberveglieri G. An array of MOx sensors and ANNs to assess grated Parmigiano reggiano cheese packs' compliance with CFPR guidelines. Biosensors. 2020;10:10. doi: 10.3390/ BIOS10050047.

[75] Tonezzer M, Thai NX, Gasperi F, Duy NV, Biasioli F. Quantitative assessment of trout fish spoilage with a single nanowire gas sensor in a thermal gradient. Nanomaterials. 2021;22:1604. doi: $10.3390 /$ nano11061604.

[76] Tonezzer M. Single nanowire gas sensor able to distinguish fish and meat and evaluate their degree of freshness. Chemosensors. 2021;9:9249. doi: 10.3390/ chemosensors 9090249.

[77] Cui S, Cao L, Acosta N, Zhu H, Ling PP. Development of portable e-nose system for fast diagnosis of whitefly infestation in tomato plant in greenhouse. Chemosensors. 2021;9:297. doi: $10.3390 /$ chemosensors9110297.

[78] Astuti SD, Tamimi MH, Pradhana AAS, Alamsyah KA, Purnobasuki H, Khasanah M, et al. Gas sensor array to classify the chicken meat with $\mathrm{E}$. coli contaminant by using random forest and support vector machine. Biosens Bioelectron. 2021;9:100083. doi: 10.1016/j.biosx.2021.100083.

[79] Andre RS, Facure MHM, Mercante LA, Correa DS. Electronic nose based on hybrid free-standing nanofibrous mats for meat spoilage monitoring. Sensors Actuators, B Chem. 2022;353:131114. doi: 10.1016/j.snb.2021.131114.

[80] Carmona EN, Sberveglieri V, Ponzoni A, Zappa D, Pulvirenti A. Detection of microbial contamination in potable water by nanowire technology. Int J Smart Sens Intell Syst. 2014;7:2-5. doi: 10.21307/IJSSIS-2019-054.

[81] Carmona EN, Sberveglieri V, Comini E, Zappa D, Pulvirenti A. Nanowire technology for the detection of microorganisms in potable water. Procedia Eng. 2014;87:1453-6. doi: 10.1016/ j.proeng.2014.11.723.

[82] Sberveglieri V, Nunez Carmona E, Comini E, Ponzoni A, Zappa D, Pirrotta O, et al. A novel electronic nose as adaptable device to judge microbiological quality and safety in foodstuff. BioMed Res Int. 2014;2014:529519. doi: 10.1155/ $2014 / 529519$.

[83] Saidi T, Welearegay TG, Zaim O, Leon OG, Ionescu R, El Bari N, et al. Ability of discrimination of breath from smoker and nonsmoker volunteers by using an electronic nose based on $\mathrm{WO}_{3}$ nanowires and $\mathrm{SnO}_{2}$ sensors. ISOEN 2017 - ISOCS/IEEE Int Symp Olfaction Electron Nose, Proc. 2017;13:15-7. doi: 10.1109/ISOEN.2017.7968881.

[84] Núñez Carmona E, Sberveglieri V, Ponzoni A, Galstyan V, Zappa D, Pulvirenti A, et al. Detection of food and skin pathogen microbiota by means of an electronic nose based on metal oxide chemiresistors. Sensors Actuators, B Chem. 2017;238:1224-30. doi: 10.1016/j.snb.2016.09.086.

[85] Soprani M, Ponzoni A, Sberveglieri V, Carmona EN, Bhandari MP, Betto G, et al. Real-time chemical gas sensing of pathogenic microorganisms pollution in wastewater. ISOEN 2017 - ISOCS/IEEE Int Symp Olfaction Electron Nose, Proc. 2017;13:17-9. doi: 10.1109/ISOEN.2017.7968877.

[86] Zappa D, Bertuna A, Comini E, Kaur N, Poli N, Sberveglieri V, et al. Metal oxide nanostructures: preparation, characterization and functional applications as chemical sensors. Beilstein J Nanotechnol. 2017;8:1205-17. doi: 10.3762/ bjnano.8.122.

[87] Soprani M, Duina G, Malgaretti M, Abbatangelo M, Sberveglieri V. Array of semiconductor nanowires gas sensor for IoT in wastewater management. IEEE/ACM transactions on computational biology and bioinformatics. 2018;13:68-71. doi: 10.1109/METROI4.2018.8438882.

[88] Binson VA, Subramoniam M, Mathew L. Detection of COPD and Lung Cancer with electronic nose using ensemble learning methods. Clin Chim Acta. 2021;523:231-8. doi: 10.1016/ j.cca.2021.10.005.

[89] Chen PC, Sukcharoenchoke S, Ryu K, De Arco LG, Badmaev A, Wang $C$, et al. 2,4,6-Trinitrotoluene (TNT) chemical sensing based on aligned single-walled carbon nanotubes and $\mathrm{ZnO}$ nanowires. Adv Mater. 2010;22:1900-4. doi: 10.1002/ adma.200904005.

[90] Ponzoni A, Comini E, Concina I, Ferroni M, Falasconi M, Gobbi E, et al. Nanostructured metal oxide gas sensors, a survey of applications carried out at SENSOR Lab, Brescia (Italy) in the security and food quality fields. Sensors. 2012;12:17023-45. doi: 10.3390/s121217023. 
[91] Adib M, Sommer M. UV excited $\mathrm{SnO}_{2}$ nanowire based printed e-Nose. Proc IEEE Sensors. 2017;2016:7808805-56. doi: 10.1109/ICSENS.2016.7808805.

[92] Liang C, Li Y, Luo J. Development of electronic nose based on ZnO nanowires for toxic gas detection. Proc 2017 3rd IEEE Int Conf Sensing, Signal Process Secur ICSSS 2017. 2017;13:275-8. doi: 10.1109/SSPS.2017.8071605.

[93] Adib M, Eckstein R, Hernandez-Sosa G, Sommer M, Lemmer U. $\mathrm{SnO}_{2}$ nanowire-based aerosol jet printed electronic nose as fire detector. IEEE Sens J. 2018;18:494-500. doi: 10.1109/ JSEN.2017.2777178.

[94] Suzuki M, Miyauchi T, Isaji S, Hirabayashi Y, Naganawa R. Decay detection of constructional softwoods using machine olfaction. J Wood Sci. 2021;67:62. doi: 10.1186/s10086-021-01995-3.

[95] Maccato C, Bigiani L, Carraro G, Gasparotto A, Sada C, Comini E, et al. Toward the detection of poisonous chemicals and warfare agents by functional $\mathrm{Mn}_{3} \mathrm{O}_{4}$ nanosystems. ACS Appl Mater Interfaces. 2018;10:12305-10. doi: 10.1021/acsami.8b0183.

[96] Bigiani L, Zappa D, Barreca D, Gasparotto A, Sada C, Tabacchi G, et al. Sensing nitrogen mustard gas simulant at the ppb scale via selective dual-site activation at $\mathrm{Au} / \mathrm{Mn}_{3} \mathrm{O}_{4}$ interfaces. ACS Appl Mater Interfaces. 2019;11:23692-700. doi: 10.1021/acsami.9b0487.

[97] Bigiani L, Zappa D, Maccato C, Gasparotto A, Sada C, Comini E, et al. $\mathrm{Mn}_{3} \mathrm{O}_{4}$ nanomaterials functionalized with $\mathrm{Fe}_{2} \mathrm{O}_{3}$ and $\mathrm{ZnO}$ : Fabrication, characterization, and Ammonia sensing properties. Adv Mater Interfaces. 2019;6:1901239. doi: 10.1002/ admi.201901239.

[98] Bigiani L, Zappa D, Maccato C, Comini E, Barreca D, Gasparotto A. Quasi-1D $\mathrm{MnO}_{2}$ nanocomposites as gas sensors for hazardous chemicals. Appl Surf Sci. 2020;215:145667. doi: 10.1016/j.apsusc.2020.145667. 